\title{
2 \\ Extension Problem: Resolution Through an Unexpected Source
}

\author{
Dwight Read
}

I said, indeed, that the science of colour was mathematical ... the absolute certainty of a science cannot exceed the certainty of its principles ... And if these principles be such that on them a mathematician may determine all the phenomena of colours ... the science of colour will be granted mathematical (Sir Isaac Newton 1782 [1672]: 342). ${ }^{1}$

\section{Prologue}

A long-standing issue in kinship theory stems from the presence of kinship terminologies with kin terms having genealogical referents crosscutting, rather than following, the pattern for genealogical relations. The notion that the genealogical referents should be in agreement with genealogical relations arises from the assumption, going back to Lewis Henry Morgan, that the kinship relations identified through a kinship terminology are based on procreation in conjunction with marriage. If both kin terms and genealogical relations are determined mainly through procreation, then, at first glance, it appears that they should be mutually consistent, but this is not the case for some terminologies. Despite attempts from Morgan onwards to account for this seeming anomaly, the issue still

1 I thank Burt Voorhees for bringing this quote to my attention. 
remains unresolved. Much of the writing of Harold Scheffler, both alone and in conjunction with Floyd Lounsbury, was directed towards a possible resolution of the 'extension problem' of a terminology having kin terms with both close and distant genealogical referents. They proposed that a kin term has a primary meaning expressed through the genealogical referent(s) closest, in a culturally meaningful way, to speaker and a secondary meaning provided by the other referent(s). The primary meaning, they argued, derives from procreation and so the resolution task becomes, from their perspective, one of addressing the secondary meanings that do not derive from procreation in any obvious way. Their solution involved first relating the secondary referents to the primary ones and then accounting for why more distant genealogical referents should be so equated as genealogical referents of a kin term.

Their project was only partially successful. They implemented the first part of the project through formal equivalence rules that reduced the secondary referents to the primary ones, but the second part became mired in debates over whether the equivalence rules had cultural saliency or merely provided an elegant, formal descriptive account of a terminology. Though their project did not achieve all of its goals, it did establish that terminologies are not just a collection of terms with genealogical referents whose patterning is determined by external factors such as the group organisation of the society in question, as argued by Edmund Leach (1958) for the Trobrianders. Instead, their work implied that terminologies must have an internal logic, thereby contributing to our understanding of what is common across terminologies despite surface differences. It is here where Scheffler's work will leave an enduring mark.

In my contribution to this Festschrift, I begin, in effect, where the work of Scheffler and Lounsbury left off, namely by working out the internal logic of kinship terminologies and using this logic to resolve the extension problem. Another motivation for so doing, beyond its relevance to furthering our understanding of kinship systems by resolving the extension problem, relates to whether it is culturally reasonable to consider kinship terminologies as being mathematical in the manner expressed in the epigraph to this chapter when we replace the word 'colour' by the phrase 'kinship terminologies', hence amenable to formal analysis in a culturally salient manner using mathematical reasoning. A positive answer would confirm what W.H.R. Rivers foresaw as a possibility: 'the time will come when ... parts of the description of social systems of savage tribes will resemble a work on mathematics' (1914: 10). 
Carrying out this enterprise in toto requires rethinking widespread assumptions such as 'kin categories are genealogically structured' and 'kinship space is built up recursively out of genealogical primitives' (Jones Chapter 11) that have led to an ontology going from procreation to genealogical relations to categories of genealogical relations to kin terms as labels for those categories and then replacing this ontology with a different one. The different ontology is based on tracing the implications of the cultural knowledge that culture bearers bring to bear when they compute kinship relations directly from kin terms without reference to the genealogical relations that supposedly are the underpinnings of those terms. Considering kinship terminologies from this perspective has been surprisingly fruitful and leads to resolution of the extension problem by showing that the extensions are the consequence of the generative logic giving structure to kinship terminologies. ${ }^{2}$ To go from where Scheffler and Lounsbury left off to this resolution of the extension problem, though by a different route than the one they followed, is the primary goal of this chapter and is necessarily a long trip, but hopefully one worth taking, as it validates the basic ideas that Scheffler had about the extension of kinship terms, but by a different means than the one he used.

\section{Introduction}

The distinctions among, and organisation of, the terms making up a kinship terminology relate to various aspects of social systems through the kinship relations they represent. These kinship relations have generally been viewed, since the time of Lewis Henry Morgan (1871), from the perspective of being formed either through procreation or through marriage. Typically, analysis begins by working out the distribution of kin terms over genealogical positions in accordance with the genealogical method introduced by Rivers (1910, 1912; see also Warren Shapiro Chapter 1). In the genealogical method, informants are asked for the kin terms that would be used by speaker for persons in various genealogical positions with respect to speaker. The underlying presumption has been that the structural pattern of kin terms over genealogical positions should reflect the structural organisation of genealogical relations, though

2 In email correspondence, Warren Shapiro suggested to me the possibility that the generative logic underlying kinship terminology structure addresses the extensionist problem (2009). What I present here is my follow-up to his suggestion. 
modified according to the way the social organisation of a society relates to, and is expressed through, the kinship relations corresponding to the kin terms. However, from the very start of Morgan's systematic study of kinship terminologies, terminologies like that of the Seneca (Iroquois) presented an anomaly by virtue of having kin terms with genealogical referents that crosscut the structural pattern of genealogical relations. In the Seneca terminology, the kin term no-yeh' ('mother') (and similarly $h \ddot{a}-n i b$ ' ('father'), is used not only for mother, a lineal relation, but also for collaterally related females in her generation, meaning that the terminology does not systematically distinguish lineal from collateral genealogical relations. ${ }^{3}$ Morgan, through his background as a lawyer, was familiar with the importance of this genealogical distinction for English family law regarding inheritance. Accordingly, he divided terminologies into those that consistently keep lineal genealogical relations separate from collateral relations and those that do not. He referred to the former as descriptive terminologies and to the latter as classificatory terminologies. In his scheme, the English terminology is descriptive and the Seneca terminology is classificatory. ${ }^{4}$

With regard to the occurrence in some societies of the classificatory terminologies, Morgan asked: Why should a term used for individuals with a close, lineal relation to speaker also be extended to speaker's distant collateral relatives? In particular, why should there be kin terms such as no-yeh' and hä-nib' that refer to mother and father, respectively, as well as to persons in collateral positions of the same generation and sex as mother and father? This disjunction between the pattern of genealogical relations corresponding to kin terms in what he called the classificatory terminologies and the pattern of genealogical distinctions derived through procreation has come to be known as the extension problem. For what reason are there terminologies in which genealogical referents of a kin term are extended from close, lineal genealogical relations consistent with procreation to more distant, collateral genealogical relations for some of the kin terms?

3 Because an English word such as mother can either refer to a genealogical relation or to a kin term, I will use italics when the word refers to a kin term. The English kin-term translation for a nonEnglish kin term will be given in single quotes.

4 The classificatory part of Morgan's two-part typology has subsequently been divided into bifurcate merging terminologies in which the lineal terms merge together both lineal and collateral genealogical relations as their referents and the lineal line of kin terms are bifurcated into terms that distinguish between matrilateral and patrilateral relations, and generational terminologies that primarily distinguish between sex and generation of the kin-term referents. 
Morgan's answer to this question derives from his assumption that kinship relations are determined either through procreation or marriage. If the pattern for the genealogical referents of a kin term does not derive from procreation, as was evident for the Seneca terminology, then it must derive from marriage or a combination of procreation and marriage. Accordingly, Morgan hypothesised an earlier practice of group brothersister marriage as a way to account for terminologies with kin terms that include both lineal and collateral genealogical referents. This, however, was subsequently dismissed as empirically unfounded (but see Knight 2011 for an alternative viewpoint), leaving the extension problem unresolved.

The solution to the extension problem that will be presented here requires reconsidering the widespread assumption that kin terms are primarily names for already established categories of genealogical relations. This leads me to ask whether the kinship relations labelled by the kin terms making up a kinship terminology are derived directly from primary relations, such as the relations linking family members. The (positive) answer to this question leads me to the discovery that kinship relations identified through kin terms can be derived directly from the family relations through a computational logic based on the way culture bearers determine kinship relations directly from kin-term usage. Once this logic has been worked out, I can then show how the extension problem is resolved by reference to an unexpected source for a solution, namely whether siblings are culturally understood as those persons who share the same parents as oneself rather than as the children of one's parents other than oneself. These two ways of conceptualising siblings are biologically equivalent, but differ according to whether parents are viewed from the sibling's perspective as having commonly shared ascendants or from the parent's perspective as their descendants. As we will see, the first way for conceptualising siblings both underscores extension of the referents of kin terms from lineal to collateral genealogical relations and accounts for Morgan's distinction between descriptive and classificatory terminologies. This makes the distinction between these two kinds of terminologies, and the presence of terms in the classificatory terminologies that include both collateral and lineal genealogical referents, a consequence of properties internal, rather than external, to the kinship system. 


\section{Previous attempts to solve the extension problem}

Like Morgan's proposed solution, possible answers to the extension problem offered subsequent to him have also been problematic. Some have used a semantic/linguistic approach to resolve or even dismiss the problem (Buchler and Selby 1968). Notably, Alfred Kroeber (1909) attempted to dismiss the problem by asserting that Morgan had erred in making a distinction between descriptive and classificatory terminologies in the first place since, in his view, all terminologies have kin terms that are classificatory in their scope, but his argument rests upon a misreading of Morgan's classificatory/descriptive distinction. Morgan's distinction is not based on whether kin terms are descriptive or classificatory (Kroeber's misreading), but whether the terminology structurally and consistently distinguishes between lineal and collateral genealogical relations. Morgan was fully aware that English terms such as English uncle or aunt are classificatory in Kroeber's sense, yet the English terminology is descriptive in his schema since the kin terms with lineal genealogical referents do not include collateral referents. ${ }^{5}$

Subsequent to Kroeber, Arthur Maurice Hocart (1937) and Joseph Daniel Unwin (1929) also dismissed the extension problem. They each considered the problem to be an artefact of how the problem was defined in the first place. Hocart considered that assigning a primary and an extended meaning to a kin term reflected more the way kin terms were elicited and learned by the ethnographer than the cultural reality of the primary/extended distinction. Thus, he argued, the term tama in Melanesian terminologies ought to be translated as 'all males of the previous generation on the father's side' (Hocart 1937: 546) in an undifferentiated sense, rather than as tama meaning, first of all, father, and then, by extension, 'father's brother, father's father's brother's sons and so on' (ibid.: 545). However, whether a term such as tama should be considered polysemic (Scheffler's position, discussed below) or monosemic (Hocart's and Unwin's position) does not resolve the problem identified

5 See, for example, Morgan's (1871) comment regarding the English terminology: 'the second [collateral line], uncle, cousin, cousin's son, and cousin's grandson ... reveal[s] a tendency to avoid the full descriptive phrases. It is evident from the present structure and past history of the English system ... [that] an uncle was described as father's brother, or mother's brother [italics in the original, bold added]' $(32,33)$. 
by Morgan regarding the discordance between the genealogical referents of the term and the structural pattern of genealogical relations. Instead, viewing kin terms monosemically mainly changes what a resolution to the problem needs to address.

Others, such as Edward Evan Evans-Pritchard (1929, 1932), Brenda Seligman (1929), and Bronisław Malinowski (1927a, 1930) used a social learning approach to account for the presumed kin-term extensions going from primary to extended meanings (Buchler and Selby 1968). In this approach, the extensions are considered to be psychological phenomena reflecting how behaviour patterns are learned by a growing child, initially in accordance with a child's close, genealogical relations and subsequently extended to more distant genealogical relations. Evans-Pritchard (1929), for example, argued for the extension of the emotions and sentiments expressed within the family to individuals outside of the family as the source for kin-term extensions. For Malinowski, more was involved than the extension of sentiments within the family to those outside of the family. Malinowski considered the so-called classificatory terms to result from a gradual substitution process through which the child undergoes vicarious parent substitutions involving close kin relations in which 'the substitute parent resembles in certain respects the original one and ... the naming [of kin terms] expresses this partial assimilation' (1962: 73). As others have pointed out, though, Malinowski incorrectly equates the learning process of a child with the evolutionary origin of the kin terms whose meanings are being learned by the child. In addition, no criterion is provided for when the substitution process should occur and when it should not, hence the argument becomes circular when used to resolve the extension problem.

Other scholars such as A.R. Radcliffe-Brown, though accepting the assumptions made by Morgan, included properties in addition to those of reproduction and marriage as a way to account for the extensions. Radcliffe-Brown (1950) hypothesised, as a solution to the extension problem, what he dubbed 'the equivalence of siblings', meaning that a term used for one sibling would be used in the same manner for all other siblings. According to this hypothesis, if speaker refers to genealogical father by the kin term 'father', then speaker would extend that kin term to speaker's father's brother. However, Radcliffe-Brown did not provide a criterion for when the hypothesis is applicable (Murdock 1949); hence every terminology should be classificatory according to his hypothesis if 
it applies at all. Also problematic, his hypothesis did not address features common to classificatory (but not descriptive) terminologies such as an older/younger distinction in the referents of the sibling kin terms. ${ }^{6}$

\section{A formal attempt to resolve the extension problem}

\section{Primary versus secondary meaning of kin terms}

The extension problem has also been addressed formally, first by Floyd Lounsbury $(1964,1965)$ with regard to the logic of kinship terminologies, then with Harold Scheffler (especially Scheffler and Lounsbury 1971), and subsequently by Scheffler alone (see in particular, Scheffler 1978) with regard to the semantics of kinship terminologies. They, too, assumed that kinship relations are engendered through procreation, but avoided turning to marriage as the basis for the extension of the genealogical referents of kin terms. They accomplished this by separating the category of genealogical referents into two parts: (1) primary (or kernel) referents consisting of close genealogical relations and (2) secondary referents consisting of the more remote genealogical relations (Lounsbury 1965: 149). For the classificatory terminologies, the primary referents of a kin term are its lineal referents and the collateral referents its secondary referents. For a descriptive terminology, such as the English terminology, the primary referents include most, if not all, of the genealogical referents of a kin term; for example, the primary referents of English uncle are father's brother and mother's brother. After determining the primary referents, they constructed equivalence rules that formally relate the secondary meanings to the primary meanings.

6 The matter is more complex, though, than just not addressing the older/younger distinction. The term translated as 'older brother' or 'older sister' is, in some classificatory terminologies, also used for a reference person younger than speaker. In the Tongan terminology, a male speaker refers to the son of the older brother of father as ta'okete ('older same-sex sibling') regardless of their relative ages, even though the terminology makes no distinction between father and father's brother, with both of these males referred to as tamai ('father') (Biersack 1982: 184). From an ascending/ descending perspective (discussed below), ta'okete would be 'ascending same-sex sibling.' Since tamai is an ascending primary term, 'son' of tamai can be considered to be part of the ascending kin-term structure and so referring to 'son' of tamai as ta'okete for the older brother of father, regardless of the relative ages of speaker and alter, is structurally consistent. 
Their methodology of equivalence rules has played a central role in our understanding of the semantics of kinship terms (McConvell Chapter 7) and was utilised extensively by David Kronenfeld (2009) as part of his analyses of the kinship terminology of the Fanti in Ghana, Africa, from a behavioural perspective. Since others have already discussed the widely appreciated ground-breaking character of Lounsbury's work in detail, there is no need to review it further here. In addition, the importance of Scheffler's contribution to this work is also well established, as discussed in the Introduction and in the chapter by Patrick McConvell, hence also needs no further elaboration. Instead, the thread I take up in this chapter relates to the reasons, despite the important contribution that equivalence rules have made to our understanding of the logic of kinship terminologies, that these rules do not resolve the extension problem. Then I show that, in lieu of considering kin terms formally as a means for the categorisation of genealogical relations, if we trace out, instead, the implications of the logic by which culture bearers compute kinship relations directly through the kin terms making up their kinship terminology (which may be done without reference to genealogical relations), we now find a solution to the extension problem. ${ }^{7}$

The underlying problem with the equivalence rules as explanation for kin-term extensions is that they leave unanswered the reasons why terminologies like the classificatory terminologies deviate so widely in both their semantic and their syntactical form from the genealogical framework generally assumed to be the basis for the systems of kinship relations expressed through kinship terminologies. More specifically, Lounsbury and Scheffler's proposed resolution of the extension problem through equivalence rules has three critical problems (discussed below) that limit their role to one of identifying clues leading to answers, rather than providing the answers, with regard to questions about intersystem differences in the structure and organisation of kinship terminologies. ${ }^{8}$

7 Other formalism accounts include the book by the mathematician Sydney Gould (2000) aimed at improving on the equivalence rules and the book by Pin-Hsiung Liu (1986) aimed at formally showing how the genealogical space is structured by a kinship terminology. With regard to Gould's book, Scheffler (2002: 295) comments that his attempt to improve on the formalism of equivalence rules 'has to be reckoned a complete failure'. Anna Wierzbicka (2016: 409 n1) criticises Gould for the lack of natural language evidence justifying his assumption, made for formal reasons, that 'father's child' and 'mother's child' are primary relations.

8 The limitations apply equally to the work of Gould (2000). These limitations also include the circularity that enters in when the equivalence rules are read as being explanatory of the extension problem, since delineation of the rules requires already knowing both the structural organisation of kin terms as a kinship terminology and the genealogical definitions of kin terms. 
Another major concern is the issue raised virtually a half-century ago by Kris Lehman-perhaps the foremost scholar in the area of integrating mathematical reasoning with anthropological theorising. Lehman recognised that the equivalence rule analysis relied upon a formally naïve (in a mathematical sense) notion of genealogy that leads to a genealogical space infinite in size, hence exceeding the capacity of the human mind to consider all possible genealogical relations making up a genealogical space in a holistic sense (Lehman 2011). This implied, he pointed out, that a kinship terminology system, supposedly derivative from a genealogical space (see Jones Chapter 11), cannot provide the kind of holistic analysis presumed by the methodology of equivalence rules. Instead, he argued, rather than relying on an intuitively understood genealogical space expressed through the notational system of kin types, the methodology of equivalence rules needs a well-formulated mathematical representation of the genealogical space before one can adequately define, in a conceptually closed manner (see Leaf and Read 2012; Jones Chapter 11), what would formally constitute an adequate extension-based analysis of kinship terminologies. Accordingly, Lehman developed a mathematical representation of the genealogical space that he referred to as the Primary Genealogical Space (PGS) (see Lehman and Witz 1974). From this perspective, a formal system should, for example, encompass Kronenfeld's (2009) formal representation of the Fanti kinship terminology.

Subsequently, and building on the arguments of Read, Lehman came to realise that the entire equivalence rule enterprise was inadequate and could not achieve its goals:

Lounsbury's rewrite system said nothing about the organization of the genealogical space itself ... [and] there is no evidence to suggest that ... compacting of PGS [through rewrite rules] generates the actual structure of any KTS [Kin Term Space] (2011: 260, 262).

That is, the rewrite rules leave unexplained precisely what we want to understand, namely the basis upon which one kinship terminology differs structurally from another kinship terminology. As Lehman notes:

Read and his colleagues (Behrens and Read 1993; Read and Behrens 1990; Read 2001, 2007, 2010a, 2010b; Bennardo and Read 2005, 2007) have shown persuasively that a KTS has a distinct algebraic structure that is not all that much like PGS, and that is altogether unlikely to be generated by the compacting of PGS (2011: 264). 
Where, by 'compacting', Lehman means the equivalence rule mapping of genealogical relations expressed through kin-type notation to the extended meaning of the kin terms making up a kinship terminology. It is precisely an analytical foundation suitable for explicating the structure of a kinship terminology that is lacking in the formalism developed by Lounsbury and Scheffler, a lack that stems from the following three problems with their equivalence rules paradigm.

\section{Problem 1: Description versus explanation}

By itself, the distinction between primary and secondary referents only describes, but does not explain, the structural difference between descriptive and classificatory terminologies, as Lounsbury (1965: 175-81) recognised. Scheffler and Lounsbury attempted to build explanation into the primary/secondary distinction through the equivalence rules, but the rules are open ended (Chomsky 1963); that is, there is no restriction on what can be an equivalence rule. Thus it is always possible to make the extended, genealogical referent of a kin term equivalent to a primary referent with a rule such as: 'Rewrite the non-primary genealogical referents for a kin term as a primary genealogical referent for that kin term', with one rule per term, along with the stipulation that the rule applies only to that term. Consequently, just being able to formally reduce the extended genealogical referents of kin terms to primary referents through equivalence rules only describes how the extended referents of a kin term can be related to its primary referents (Keen 1985), not why the extensions occurred in the first place (Read 2000).

\section{Problem 2: Equivalence rules provide a window only partially opening onto the structural logic of kinship terminologies}

Though equivalence rules, by themselves, are not explanatory, nonetheless the rules indicate that there is an underlying logic to kinship terminologies since many of the rules are not terminology specific. As Roy D'Andrade has commented: 'it is reassuring that most analyses [of kinship terminologies] can be accomplished with only a few rules' (1970: 112-13). The parsimony of the rules used to formally connect the primary and secondary referents of a kin term suggests that there is a structural logic by which the kin terms form a coherent whole, but they do not make that logic evident. As Keen has put it, the equivalence rules 'may be said to capture "underlying principles" in some sense [emphasis added]' (1985: 82). It is through making the logic of those underlying 
principles complete, and not the equivalence rules, per se, that provides, as we will see, the means to effect a culturally salient resolution to the extension problem.

\section{Problem 3: Cultural saliency}

Scheffler and Lounsbury (1971) recognised that the equivalence rules do not provide an explanatory account unless they are meaningful to the users of the terminology. Though Lounsbury sketched out a possible sociological justification for the equivalence rules he had adduced for the Trobriand terminology, he also considered his sketch to only be 'a suggestion as to the kinds of data in which we might expect to find some answers' (1965: 180). Yet with regard to the kinship terminology of the Fanti, instead of finding ethnographic support for equivalence rules, Kronenfeld (2009) discovered that the rules were not meaningful to the Fanti. Kronenfeld had analysed their terminology in two ways: first, through an equivalence rules account based on the formalism of Lounsbury (1964, 1965) that he referred to as an ' $\mathrm{L}$ analysis', and second, through the way the Fanti determined the kinship relation between two individuals directly from kin terms without reference to genealogical relations using what Kronenfeld referred to as the relative products of kin terms (actually, kin-term products, as discussed below). ${ }^{9}$ Kronenfeld referred to the latter as an ' $\mathrm{F}$ analysis' and commented that the Fanti 'explained or justified their terminological assignment of kinsmen [emphasis added]' (2009: 60) through the 'logic contained in the relative products'. He observed that:

The F analysis seems closer to the way Fanti define their own kin terms than does the $\mathrm{L}$ analysis. It is based on the categories that the Fanti use, and it performs the operations on these categories that Fanti informants were observed to use ... the $\mathrm{F}$ analysis is psychologically real in the sense that it very directly represents what my informants did in their heads when they themselves calculated correct kinship relations (ibid.: 67).

For the Fanti, it is the ' $\mathrm{F}$ analysis', based on products of kin terms, and not the ' $\mathrm{L}$ analysis', based on equivalence rules, that is culturally salient. Kris Lehman makes much the same point with regard to the Lai (Haka) Chin among whom he did fieldwork:

9 As noted by Lehman (2011: 264-65), 'kin term products ... are algebraically not the same thing as the relative products of kin type strings.' 
Any speaker simply knows that, for example, $\mathrm{C}[f a]$ of $\mathrm{B}[\mathrm{u}-n a a u]=\mathrm{C}[f u]$, whilst $\mathrm{C}$ of $\mathrm{Z}[\mathrm{far}]=$ grandchild $[t u]$. One can more or less indirectly deduce such equations from the logic of the PGS > KTS morphism map [i.e. from the equivalence rules], but that is demonstrably not what native speakers $d o$; it is not how they represent or talk about such knowledge [emphasis added] (2011: 264).

Despite recognising its cultural saliency, Kronenfeld rejected the $\mathrm{F}$ analysis for comparative purposes since the Fanti categories and relations among them are not universal, whereas, he argued, the units for the $\mathrm{L}$ analysis are derived from a genealogical space that is universally applicable: '[T] he categories and operations of [the F] analysis are too peculiar to the Fanti to make them a good basis for comparing the Fanti system with others' (Kronenfeld 2009: 70). Kronenfeld reconciled the two kinds of analysis by viewing them as having different purposes, hence different criteria for analytic validity: criteria relating, he asserts, to psychological reality in the case of the $\mathrm{F}$ analysis and to the requirements of intersystem comparison for the $\mathrm{L}$ analysis (ibid.: 70; see also Keen 1985). ${ }^{10}$ The value of the $\mathrm{L}$ analysis, he says, lies in 'how well it facilitates comparison of the given system with other similar ones' (Kronenfeld 2009: 69), and the $\mathrm{L}$ analysis, he argues, unlike the $\mathrm{K}$ analysis, identifies 'the different means by which different kinds of social facts can affect a terminology' (ibid.), which presumes that social facts are the driver of terminological distinctions, a proposition found wanting in previous attempts to resolve the extension problem through, for example, marriage rules.

While Kronenfeld observes correctly that some of the specific properties of the Fanti terminology are not universal, his conclusion that this obviates intersystem comparison through what he calls an F analysis is not correct unless one were to limit comparison to using the units and kin-term products of the Fanti terminology. Obviously, units specific to the Fanti terminology cannot be treated as universal units upon which intersystem comparison of structural differences among kinship terminologies should be based. What Kronenfeld did not recognise, though, is that the principles leading to the generation of a kinship terminology from primary kin terms - the latter being the kin terms specifying family relations

10 This dichotomy is rejected by Anna Wierzbicka (2016) on the grounds that one and the same analysis can both elucidate the cognitive/psychological operations employed by the users of a terminology and enable a cross-cultural comparison of terminologies. 
(Read, Fischer and Lehman 2014)—leads universally to computational systems enabling culture bearers to determine kinship relations (Read 2007; Leaf and Read 2012; Read, Fischer and Lehman 2014), and these computational systems can be the basis for comparison. ${ }^{11}$ It is the structure generated from the units of a kinship terminology, not the units themselves, through which intersystem structural comparison should be made.

What is common across kinship terminologies is a conceptually bounded set of kin terms (Leaf 2006; Leaf and Read 2012), the kin-term product (technically, a binary product) as the means for working out the structural relations among those kin terms, and culturally salient, structural equations giving a terminology structure its particular form. By recognising that intersystem comparison may be made at the level of these elements, Lehman (2011) draws the opposite conclusion as does Kronenfeld from the ethnographic facts establishing the cultural saliency of computing kin relations using kin terms and the kin-term product. Whereas Kronenfeld sees noncomparable units, Lehman perspicaciously observes:

It seems to me that one of the most significant facts ... is something that I have never been able to handle effectively from the standpoint of PGS, namely, that Read's algebraic structures are in large measure based upon the kin knowledge speakers have of the proper way to 'navigate' the KTS system ... the KTS structure is indeed independently motivated [from PGS] and ... products in KTS become a symbolic computational system [emphasis added] (2011: 264).

We can compare computational systems of kin terms with regard to their structural properties even when each is built out of different units since a structure is determined by the relations holding among units, not by the individual properties of the units, hence comparison may be made with regard to those relations rather than the properties of the units connected through those relations (see Read 2011 for examples of this kind of structural comparison across otherwise unrelated domains). For

11 Were his argument applied to the comparison of the grammars of different languages, analysis could not be made unless each language was first expressed using a universal vocabulary. Kronenfeld does not take into account the fact that structural forms are analytically comparable even when each is generated from different units and structural equations. The basis for structural differences among terminologies needs to be made evident, not simply described through translating them into a common framework such as genealogical relations organised in the form of the genealogical grid. Even here, though, the supposed universality is problematic with terminologies that have sibling kin terms differentiated by criteria in addition to sex since sibling kin types typically only incorporate sex as a distinguishing feature. 
kinship systems, we may make comparison through the product relations structurally connecting kin terms to one another, rather than through the properties of the kin terms, per se, such as their genealogical definitions. It is the logic of making kinship relation computations using primary kin terms, then, that leads, as we will see, to a resolution of the extension problem.

\section{Kin-term calculations and cultural saliency}

The kind of kin-term calculations made by the Fanti or the Lai (Haka) Chin without reference to genealogical relations is widespread and has been commented upon by numerous ethnographers (Keen 1985 and references therein), thus showing the widespread, if not universal, cultural saliency of emic calculations like this. For instance, in reference to the Kariera, a huntergatherer group in Western Australia, Radcliffe-Brown wrote:

The method of determining the relationship of two individuals is extremely simple. Let us suppose ... that two men, A and B, meet each other for the first time. The man $\mathrm{A}$ has relative $\mathrm{C}$ who is his mama. At the same time, $\mathrm{C}$ is the kaga of $\mathrm{B}$. It immediately follows that $\mathrm{A}$ and $\mathrm{B}$ are kumbali to each other (1913: 150-51).

Similarly, Marshall Sahlins comments for the Moala Fijians:

[Kin] terms permit comparative strangers to fix kinship rapidly without the necessity of elaborate genealogical reckoning-reckoning that typically would be impossible. With mutual relationship terms all that is required is the discovery of one common relative. Thus, if $\mathrm{A}$ is related to $\mathrm{B}$ as child to mother, veitanani, while $C$ is related to $B$ as veitacini, sibling of the same sex, then it follows that $A$ is related to $C$ as child to mother although they never before met or knew it. Kin terms are predicable. If two people are each related to a third, then they are related to each other (1962: 155).

In reference to the Kondaiyankottai Maravar, a Dravidian language group in southern India, Anthony Good writes:

If ego knows what term to use for alter $\mathrm{A}$, and also knows what term $A$ uses for alter $B$, he can easily work out what term he himself should use for B (1981: 113). 
With regard to the Shipibo, a horticulture group in Amazonian Peru, Clifford Behrens observes that:

Kin terms are elicited from informants without their recourse to genealogical relationships; rather, terms of reference are assigned to individuals by tracing only through the terms themselves ... Two women used the kin terms they applied to a third individual in order to determine the kin relation between their offspring and that person (1984: 146).

In the same vein, Stephen Levinson notes with respect to those living on Rossel Island in New Guinea:

Kinship reckoning on Rossel does not rely on knowledge of kin-type strings ... What is essential in order to apply a kin term to an individual $\mathrm{X}$, is to know how someone else, of a determinate kinship type to oneself, refers to X. From that knowledge alone, a correct appellation can be deduced. For example, suppose someone I call a tîdê 'sister' calls X a tp:ee 'my child', then I can call X a chênê 'my nephew', without having the faintest idea of my genealogical connection to X (2006: 18).

Laurent Dousset also makes it evident that reckoning kinship relations between individuals in this manner applies not only to the two persons in question, but also to everyone in the community:

When two foreigners can both trace their classificatory relationships towards a third person, the remaining relationships among all other members of the community can be deduced from this set [emphasis added] (2005: 22).

Others have also commented on the way kin relations can be determined directly from kin terms, such as Rusiate Nayacakalou (1955) for the TokaToka villagers in Fiji, Martin Silverman (1971) for the Banaban Islanders in Polynesia, Raymond Case Kelly (1977: 69) for the Etoro of Papua New Guinea, Masri Singarimbun (1975: 147) for the Karo Batak of North Sumatra, Joanna Overing Kaplan (1975: 181) for the Piaroa of the Orinoco Basin, Lorna Marshall (1976) for the !Kung san of Botswana, Richard Feinberg (1981: 106) for the Anuta of Polynesia, Peter Gow (1991: 193-94) for the Piro of the Peruvian Amazonia, Aparecida Vilaça (2002: 352) for the Wari' of Brazil, and Alan Barnard (2010: 252) for the Naro of southern Africa, among others. 


\section{Kin-term products}

These observations imply that if two persons know their respective kinterm relationship to a third person, then they may compute the kinship relation they have to each other through their cultural knowledge regarding how the kin terms making up their kinship terminology are interrelated. They do the computations without reference to the genealogical relations subsumed under the kin terms. I will refer to computing a kin term from a pair of kin terms in this manner as the kin-term product of that pair of kin terms. ${ }^{12}$ We may formally define (compare with the quote above from Good 1981) the kin-term product as follows:

Definition: Suppose $\mathrm{K}$ and $\mathrm{L}$ are kin terms, then the kin term product of the kin terms $\mathrm{K}$ and $\mathrm{L}$, is a kin term $\mathrm{M}$ that speaker would (properly) use (if any) for alter 2 when alter1 (properly) refers to alter 2 by the kin term $\mathrm{K}$ and speaker (properly) refers to alter 1 by the kin term L (Read 1984: 422).

I include, parenthetically, the expression 'properly' in the definition to indicate that the kin-term product refers to usage that most, if not all, culture bearers agree is correct, or view as being their way to use this kin term. I also include, parenthetically, the caveat 'if any' since even though the kin term product may be meaningful, it need not correspond to a kin term. For example, for English speakers, the product of the kin terms father and father-in-law does not correspond to an English kin term even though the kin-term product father of father-in-law is meaningful; that is, this corresponds, for English speakers, to a situation where speaker refers to a man [alter 1] as father and that man refers to another man [alter 2] as father-in-law, which is meaningful from a communication viewpoint, yet speaker does not have a kin term that refers to alter 2 . Additionally, the definition states 'is a kin term' rather than 'is the kin term' since, in some situations (though not often) the kin-term product may correspond to more than one kin term. For example, for English speakers, the kin-term product mother of 1st-cousin-once removed (where mother and 1st-cousinonce removed are kin terms) may either be the kin term 1st-cousin or the kin term great-aunt since 1st-cousin-once-removed is a self-reciprocal kin term used either for speaker's first cousin's child or speaker's great-aunt's child.

12 Read (1984) introduced the expression kin-term product to designate computations with kin terms in place of the expression relative product since the latter does not specifically refer to kin-term computations and is generally used to refer to the concatenation of genealogical relations. 
We will formally denote that the kin-term product of the kin terms $\mathrm{K}$ and $\mathrm{L}$ leads to the kin term $\mathrm{M}$ by the equation, $\mathrm{K}$ o $\mathrm{L}=\mathrm{M}$ (read: 'the product of the kin term $\mathrm{K}$ with the kin term $\mathrm{L}$, denoted by $\mathrm{Ko} \mathrm{L}$, is the kin term $M$ ' or in simple word form, ' $K$ of $L$ is $M$.' Here 'of' is formally denoted by the symbol 'o', 'is' by the symbol '=', and $\mathrm{K}, \mathrm{L}$ and $\mathrm{M}$ are kin terms, not persons or genealogical relations. Thus (for English speakers), if alter 1 refers to alter 2 by the kin term daughter $(=\mathrm{K})$ and speaker refers to alter 1 by the kin term aunt $(=\mathrm{L})$, then speaker, drawing upon her or his cultural knowledge, knows that she or he may properly refer to alter 2 by the kin term cousin $(=\mathrm{M})$ and so the kin-term product of daughter and aunt is cousin (see Figure 1); more formally, daughter o aunt = cousin. What we derive or express through the kin-term product is, or can be, expressed in a culturally salient manner. ${ }^{13}$ This does not mean that results obtained through the equivalence rules lack cultural saliency, only that the latter must be demonstrated and not assumed.

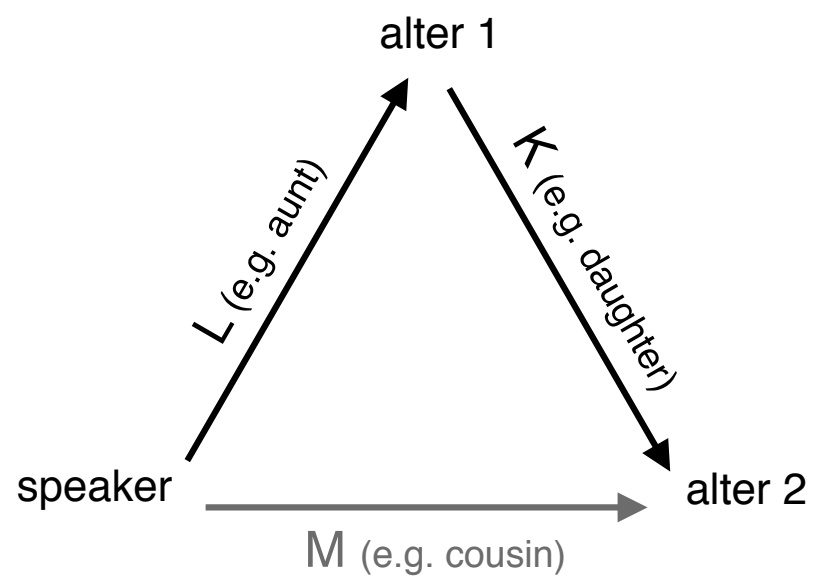

Figure 1. Kin-term product of $L$ (aunt) and $K$ (daughter) is $M$ (cousin) Labelled (black) arrows show the reference kin term (properly) used by speaker and alter 1 and by alter 1 for alter 2 . The grey arrow shows the term known from cultural knowledge to be (properly) used by speaker for alter 2 .

Source: Constructed by (c) Dwight Read.

13 Kin-term product equations can be elicited systematically from informants as Leaf (2006) discusses in detail and illustrates with the Punjabi terminology (see also Leaf and Read 2012). 


\section{Assumed genealogical basis for kin terms contradicted by ethnographic evidence}

The fact that culturally meaningful computations are made consistently by culture bearers through the kin-term product strongly suggests that a kinship terminology is not simply a list of terms corresponding to already determined categories of genealogical relations, as has generally been assumed, but has an underlying computational logic that enables culture bearers to make kin-term computations in a consistent and noncontradictory manner without reference to genealogical definitions of kin terms. From this perspective, a kinship terminology would be structured through kin-term products made with primary kin terms, where the primary terms are terms for the family relations, rather than through an ontological sequence beginning with genealogical relations. For English speakers, the primary terms include the kin terms father, mother (or parent), brother, sister (or sibling), son, daughter (or child), husband and wife (or spouse).

Thus we need to reconsider the assumption that the ontological sequence for the kinship relations expressed through the terms making up a kinship terminology is: procreation $\rightarrow$ genealogical relations $\rightarrow$ categories of genealogical relations $\rightarrow$ kin terms. In this sequence, the genealogical relations are assumed to stem from procreatively determined parent/child connections, augmented by a marriage relation that links a putative father with a presumed mother. The first part of the sequence, procreation $\rightarrow$ genealogical relations, is not problematic so long as we include the caveat that it involves procreation as it is locally understood and culturally expressed (Scheffler and Lounsbury 1971: 37), ${ }^{14}$ meaning

14 Going from procreation to genealogical relatedness is only problematic when one insists that the latter refers to a biological connection between speaker and referent; that is that a genealogy is the same as a pedigree. Numerous ethnographic accounts have established that biology is not a universal driver for genealogical relatedness, as it is locally recognised, if only because neither the statuses of motherhood nor of fatherhood from which genealogical connections are derived are constrained to biological mother and biological father. However, this does not imply the irrelevance of the biological facts underlying procreation, only that these biological facts do not universally determine cultural understanding of procreation; hence genealogical relatedness cannot be assumed universally to be constructed through biological parent and offspring. Local accounts of procreation are neither completely independent of, nor totally determined by, the biological facts. Instead, procreation is understood culturally and, while this understanding is not divorced from the biological facts, it may include aspects that are culturally recognised yet do not have a biological basis. This can be seen in the quite different accounts in various societies regarding who contributes what and under what conditions to the formation of an offspring recognised as a societal member and thereby understood to have genealogical connections to other societal members. For example, as Keen (1985) discusses, 
that culturally understood procreative relations may be conceptually disconnected from biological procreation. What is problematic in this ontological sequence, though, is the assumption that genealogical relations are first categorised by generally unspecified criteria into a relatively limited number of categories, and these are then linguistically labelled and constitute the kinship terminology.

The fundamental assumption of this ontological sequence, namely that the meaning of a kin term is first and foremost genealogical, is contradicted by numerous ethnographic accounts regarding kinship systems in which genealogical relations are neither central nor even critical to how group members understand kinship relations. With regard to the !Kung San from Botswana, Africa, for example, Lorna Marshall comments:

[They] were apparently not always assiduous in teaching their children the exact biological position of their kinsmen .... and a person would not always know why he applied a certain term to someone, but he would know that the term he used was proper [emphasis in original] (1976: 204).

In other words, the underlying genealogical relations are not of primary concern to the !Kung San. Instead, what is of concern to them are aspects of their kinship system, such as the kin tie between two persons established through name giving, that do not have a direct counterpart in genealogical (let alone biological) relations. Similarly, Shapiro refers to the difficulty his informants had in making genealogical calculations, but not calculations based on kin-term products: Aboriginal Australians easily decode the messages "aunt's children" and "X's children" but not the message "father's sister's children"” (1982: 274), and:

the Bahaya of Tanzania attribute fatherhood for a woman's first child to the man who first had intercourse with her even if that occurred more than nine months prior to her giving birth (Moller 1958), the Atta negritos in the Philippines allow for partible paternity in which more than one man can be considered to be the genitor of a child (Armando Marques-Guedes, personal communication to Ian Keen, n.d.), and the older Lusi people from Kaliai, West New Guinea assume that multiple copulatory acts are needed for foetal development, thus more than one man may contribute to this process (Counts and Counts 1983). Scheffler makes the distinction between genealogical relations and biological relations explicit when he says that for a critique made of his use of connotation and metaphor to be valid:

$[\mathrm{O}]$ ne would have to accept the absurd assumption that kinship terms refer to biogenetic relationships of the sort known only to the sciences of biology and genetics. The only tenable assumption is that they refer to relationships 'known' to or posited by the people who use the terms. The components of their significata ... are cultural constructs [emphasis added] (1972: 322; compare with Greaves and Kramer Chapter 4). 
In dealing with such relatively remote kin-types and even with close collateral kin, informants were generally more comfortable operating through the relationship terminology: it made little or no personal or social difference to them whether (say) an alleged brother of the MM was in fact a MMB or a more remote 'brother' of the MM (ibid.: 275; see also Shapiro Chapter 1).

Scheffler and Lounsbury make much the same point with regard to formalisms such as componential analysis:

$[\mathrm{F}] \mathrm{ew}$, if any informants ever offer statements about the meaning of their kin terms which correspond ... to the statements of these definitions as expressed in componential analyses ... If asked directly what the term 'cousin' means, a competent informant is likely to respond with 'my cousins are the children of my uncles and aunts', i.e. ... as a relative product [read: kin-term product] ... From our experience and that of other ethnographers (see Nayacakalou 1955), we know that in general that this is the way in which other peoples typically respond to direct questions about the 'meanings' of their kin terms (1971: 140).

They go on to discuss how children, when learning a kinship terminology, do not learn the meaning of kin terms and the relationships among terms by reference to genealogy, but directly through the kin-term product (relative product in their vocabulary):

[For] a person from a society with an Iroquois-type terminology ... the son of any man he calls 'father' is to be called 'brother' ... He need not inquire into whether the [son] is his father's long-lost brother, or his father's FBS, or his father's FZS, etc., in order to know how to classify him (ibid.: 142).

In other words, the child only needs to know that the kin-term product equation, 'son' o 'father' = 'brother' (read: " son" of "father" is "brother" for the kin terms translated as son, father and brother, respectively'), applies to any male he refers to as 'father'. He does not need to know the genealogical relation(s) involved, let alone the actual biological relations. Thus even Scheffler and Lounsbury, despite their emphasis on procreation as the basis for kinship relations, recognised that kin relations are not computed from genealogical relations simpliciter, let alone, as Jones (Chapter 11) points out, relations determined and structured by a biologically defined coefficient of relatedness. They did not explore the logic, though, of kinterm products and how this leads to a solution to the extension problem. It is this logic and its implications for solving the extension problem that I will now address in the remainder of this chapter. 


\section{The kin-term product logic of kinship terminology structures}

I begin by graphically expressing the structure for the terms making up a kinship terminology by taking kin-term products with the primary kin terms for all of the kin terms in the terminology. Figure $2 \mathrm{a}$ shows the structure for the American/English kinship terminology formed in this manner using the primary terms parent, child, and spouse, along with self, where self provides the starting point for the structure. ${ }^{15}$ The terminology has a ladder-like structure for both the lineal kin terms and the first line of collateral kin terms. Compare this with the very different, symmetric structure for the kinship terminology of the Shipibo (see Figure 2b). Yet other structural forms for kinship terminologies are presented in Read (2013). Note that the connector, 'of', in the kin-term product of a pair of kin terms, may be interpreted as a binary operator acting over each pair of kin terms making up a kinship terminology. With this interpretation, the kin-term product leads to expressing, in a natural way, a kinship terminology as having the structural form of an abstract algebra, where the latter consists of a set $\mathbf{S}$ of elements (here, $\boldsymbol{S}$ is the set of kin terms), at least one operator defined over that set of elements $\mathbf{S}$ (here, the kin-term product interpreted as a binary operator) and subject to a set of structural equations (here, the kin-term product equations giving the terminology its structural form, to be discussed below). Viewing a kinship terminology as having an algebraic structure (Read 1984) is culturally salient and leads to analysing a kinship terminology as a symbolic, computational system based on the kin-term product.

15 The American/English terminology has both sex-marked and neutral primary kin terms such as mother, father and parent. The generative logic of the American/English terminology shows that the terminology is based on the neutral primary kin terms, with sex marking introduced by bifurcating the lineal neutral kin terms such as parent, grandparent ... into sex-marked kin terms. In this way, parent becomes the 'covering' kin term for the kin terms mother and father, grandparent becomes the covering kin term for the kin terms grandmother and grandfather, and so on (see Read 2007; Read and Behrens 1990; and Leaf and Read 2012 for details). This, however, is not universally the means by which kin terms become sex marked. 


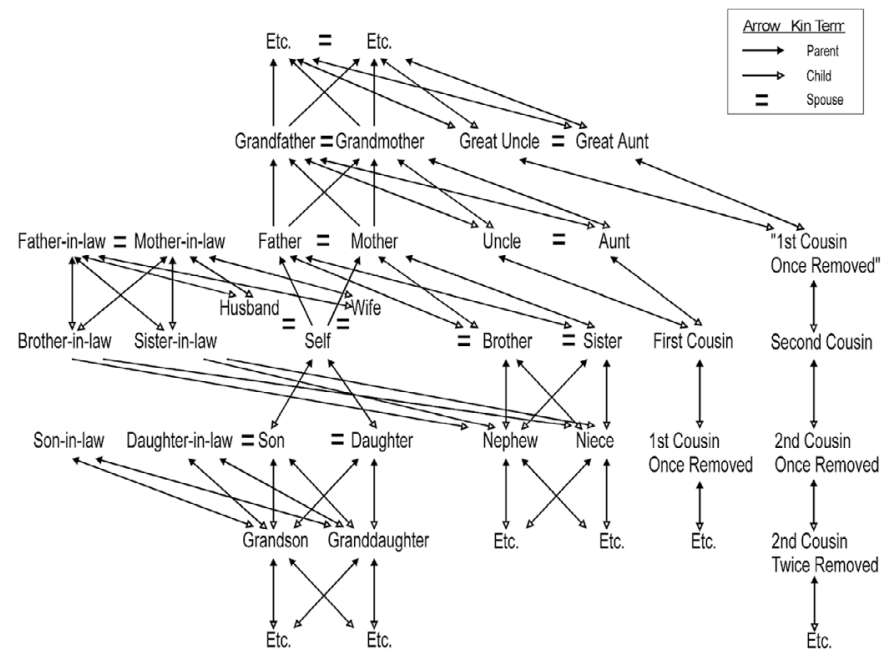

Figure 2a. Structure of the American/English kinship terminology Source: Constructed by (c) Dwight Read.

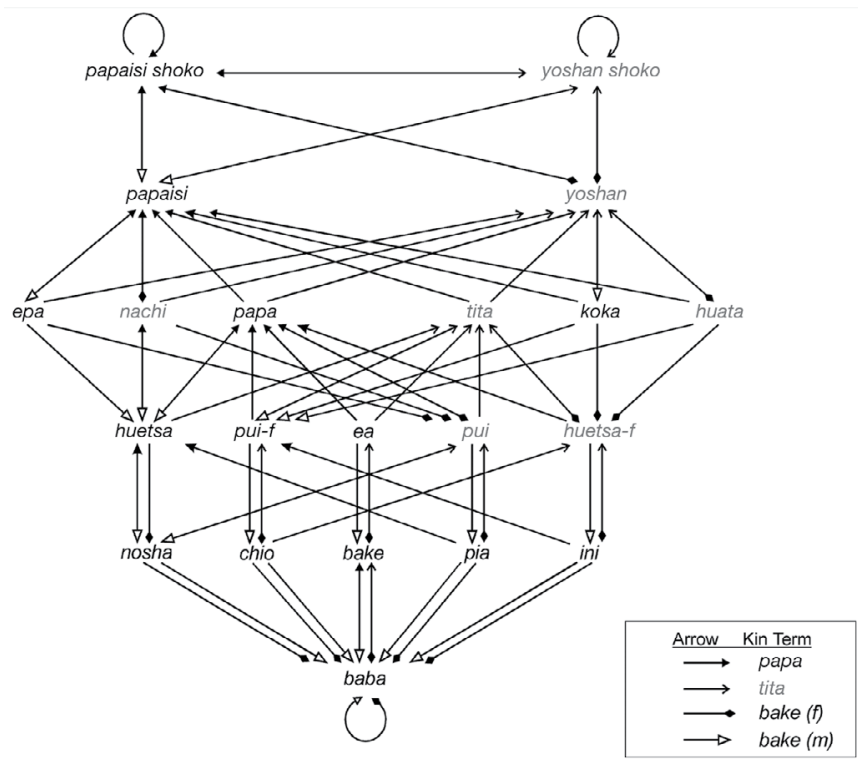

Figure 2b. Structure of the Shipibo kinship terminology

Both structures are based on kin-term products. Each arrow corresponds to a primary kin term, as shown in the key for each diagram, and shows the consequence of taking the kin-term product of a primary kin term with a kin term. Thus, the arrow with an open arrow head in Figure 2a going from the kin term aunt to the kin term first cousin shows that the kin-term product of the primary kin term child with the kin term aunt is the kin term first cousin: child o aunt $=$ first cousin.

Source: Constructed by (c) Dwight Read. 


\section{Kinship terminologies viewed as symbolic, computational systems}

Notably absent from the ontological sequence given above is the ontological basis for the various kinship terminology structures made evident through kin-term products of kin terms with primary kin terms. Morgan's attempt to account for the structural differences between the Roman terminology (used by him as a canonical example of a descriptive terminology) and the Seneca/Iroquois terminology led him to an unsuccessful excursion into hypothesised past marriage practices. Similarly, Scheffler and Lounsbury's subsequent attempt to resolve the extension problem through equivalence rules can justifiably be critiqued as insufficient for the reasons outlined above; nonetheless, their equivalence rules partially expose an underlying logic for the system of kin terms making up a kinship terminology. That there is an underlying logic is suggested by the fact that only a few rules are needed to describe the relationship between the secondary and the primary genealogical referents of the kin terms. Instead of referring to genealogical relations as a way to account for structural properties, though, the implied structural logic needs to be linked to fundamental kinship concepts, such as reciprocity of kinship relations; that is if speaker has a kinship relation to alter (expressed through the kin term $\mathrm{K}$ ), then alter has a kinship relation to speaker (expressed through a kin term L), that may be expressed through kin-term products. ${ }^{16}$ For example, for English speakers, if speaker refers to alter as child, then alter refers to speaker as parent, hence parent and child are reciprocal kin terms and parent $\mathrm{o}$ child $=\operatorname{self}$ (read 'parent of child is self) since speaker refers to himself/herself as self. (Defining reciprocity of kin terms through the kin-term product in this manner will be discussed in more detail below.) A structure derived from kinship properties like reciprocity makes it possible, as we will see, to connect kin terms to genealogical relations rather than the reverse, as has generally been assumed, and from this the extension problem may be solved. Rather than staying with the assumption that kin terms are, first of all, genealogical relations, we need, as David Schneider phrased it (but without providing a means for implementation), a different way to consider kinship terminologies other than through genealogical relations:

16 The term $\mathrm{L}$, in some cases, may be the same as $\mathrm{K}$, as occurs with the kin term sibling (= K) for English speakers. When $\mathrm{K}$ and its reciprocal term $\mathrm{L}$ are the same term, then $\mathrm{K}$ is said to be selfreciprocal. 
[T] he genealogically defined grid is the only analytic device that has been applied to most of the systems which anthropologists have studied. There has been almost no systematic attempt to study the question without employing this device. To put it simply, it is about time that we tested some other hypotheses (1972: 49).

The different way (contra the performatist view of kinship derived from Schneider and critiqued by Shapiro Chapter 1), which we will now discuss briefly (see Read and Behrens 1990; Read 2001, 2007; Leaf and Read 2012 for more complete discussions) to provide the background for resolving the extension problem, is to consider a kinship terminology as a (symbolic) computational system based on the logic of kin-term products and integrated with fundamental kinship concepts such as reciprocity of kin terms. The logic of this computational system underlies the computation of kinship relations through kin-term products in the manner well attested to in the ethnographic accounts mentioned above and leads us, as we will see, to resolution of the extension problem.

\section{From procreation to the Family Space}

As we have seen, the kin-term product enables determining kin-term relations among individuals even when relevant genealogical relations are unknown. We now turn computations like this around. Instead of kinterm products being computed using already known kin terms, we will use the kin-term product to generate new kin-term relations from the kin terms for primary relations. This enables us to use the kin-term product systematically as a way to generate the kinship relations corresponding to the terms of a kinship terminology from primary relations. In addition, the kin-term product enables prediction of the kin types (genealogical relations) subsumed under the kin terms for these generated kinship relations. The predictions are typically 100 per cent correct, thereby providing strong evidence for the validity of modelling a kinship terminology as a structure generated from primary relations. Once all of this is in place, we can then resolve the extension problem.

To carry out the argument, we first identify culturally salient, primary relations from which the kin-term relations making up a kinship terminology can be generated. These primary relations must be meaningful to culture bearers even absent the kinship terminology, just as we must have a beginning concept - the concept of singleness-for generating the counting numbers that is already understood prior to generating those 
numbers. The relations that will play an analogous role in the generation of kin-term relations will be the relations forming what we will refer to as a Family Space (Read, Fischer and Lehman 2014; see Figure 3). By a Family Space will be meant a mental construct, not the instantiation of a mental construct such as the nuclear family that is part of the phenomenal domain. As Shapiro has put it succinctly: '[the] Nuclear family is a proposition ... it emphasizes Behaviour, not Mind' (1982: 260). The Family Space can be thought of as being composed of the relations expressed through a cultural representation of procreation, not as an encoding of, or elaboration on, the facts of biological procreation.

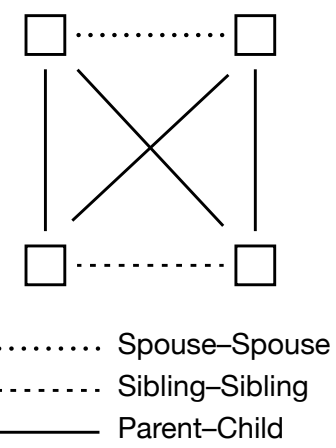

Figure 3. Minimal graph of the positions, indicated by boxes, making up a Family Space

Four positions are necessary as there is both a vertical (parent-child) division and a horizontal (husband-wife and sibling-sibling) division. A person(s) may be assigned to each position by cultural criteria.

Source: Constructed by @ C Dwight Read.

Just as 'singleness' is taken to be axiomatic for the purpose of formally generating the counting numbers, the relations making up the Family Space will be axiomatic for formally generating kin-term relations. By being axiomatic will be meant that these relations are self-evident to culture bearers without reference to a kinship terminology, in the same sense that 'singleness' is understood without reference to the counting numbers, as can be seen through the ways that 'singleness' is expressed linguistically for English speakers through phrases such as 'I have a book', 'the object over there', 'my dog is brown', and so on. Just as 'singleness' is understood without reference to the counting numbers generated from the concept of singleness, the relations of the Family Space are understood by culture bearers without reference to the kin-term relations generated from them and making up a kinship terminology. Instead, the 
family relations are understood through the way the biological facts of procreation are culturally understood and formulated. The relationship of mother to child (and reciprocally, of child to mother), for example, is initiated through (but need not be in complete accordance with) biological birth and mothering behaviours, hence does not require reference to kinterm relations to be understood. In all societies, culture bearers recognise a mother/child relation and its attendant behaviours however it may be culturally expressed and culturally instantiated (see Read 2002 for a discussion of cultural instantiation).

As shown in Figure 3, the Family Space has four positions: the mother, father, daughter and son positions, and three kinds of connections between the possible pairs of these positions. ${ }^{17}$ The first kind of connection is shown by the four vertical connections (solid lines in Figure 3) determined through motherhood and fatherhood and their reciprocal concept of childhood. From a formal viewpoint, the logical possibility of a parenthood connection from a mother or father position back to itself is excluded by the fact that selfing does not occur under biological procreation. Further, and critically, motherhood involves not only the concept of giving birth to a child, but also the idea of engaging in mothering behaviour towards that child. ${ }^{18}$ There are two child positions, indicating conceptually

17 Keen (1985) somewhat similarly builds a hierarchy of what he calls 'kin-relational expressions', starting with first-order expressions and their definitions (see his Table 1); for example, 'one's mother is the female person who gave birth to one' exemplifies what he considers to be a first-order kinrelational expression and its definition for English speakers. His goal, to establish a foundational basis upon which higher-order kin-relational expressions can be built, is similar to what is discussed here. However, Keen does not fully succeed in his endeavour since his first-order definitions are essentially biological definitions and thus take the endeavour outside of the cultural context that is germane to his task. As we know through reproductive technologies, adoption and the like, the English kin term mother does not simply refer to 'the female person who gave birth to one.' Indeed, any attempt to formally define a foundational concept such as mother runs into the problem of an infinite regress. For this reason, as has long been established in mathematics, an axiomatic system begins with terms undefined within the axiomatic system. Thus, for the Family Space we begin with, for example, mother as an undefined concept within the formalism, but a concept whose meaning is intuitively known to culture bearers. An enculturated individual 'knows' that someone is a mother, not because of a formal definition, but because of one's experience, and the experience of others, with regard to behaviours that are understood to be part of the essence of what it means to be a mother, hence mark the fact that one is dealing with an instance of the mother relation.

18 Surrogate mothers become biological mothers, but do not take on the status of motherhood by that fact alone. It is the female who has contracted for the offspring with a surrogate mother who takes on the status of motherhood, regardless of her biological connection to the offspring, by engaging in mothering behaviours legitimised through the contractual relationship with the surrogate mother. Who takes on the status of being mother, let alone motherhood, becomes uncertain, though, when the contractual relationship is violated or declared null and void. The latter has, in at least one case in Canada, led to a child not having a legally recognised mother (Baudouin and Blaikie 2014). 
the procreative property of being able to have more than one child. Second, there is a horizontal connection between the two child positions (see dashed line in Figure 3) that we can refer to as a sibling connection. From a formal viewpoint, the logical possibility of the sibling connection coinciding with the parent/child connection is excluded by the facts of biological procreation. However, the sibling connection would, according to procreation alone, still allow for three possible modalities: (1) a shared mother but not a shared father, (2) a shared father but not a shared mother, and (3) a shared mother and a shared father. Third, the first two modalities are culturally erased by marriage establishing a spouse connection between the mother and father positions and the cultural assignment of birth legitimacy through the presumption of a parent/child connection from a child position to both a male marked position and a female marked position, themselves connected by a spouse relation (see dotted line in Figure 3). ${ }^{19}$ Thus the act of marriage identifies a male as (putative) father for the future offspring-to-be of a female and her offspring are thereby culturally recognised as legitimate societal members for the social group in which the female is recognised as a proper societal member. ${ }^{20}$ Fourth, from a formal viewpoint, marriage, in and of itself, does not exclude the possibility that the spouse connection coincides with either the parent/ child connection or the sibling connection. These two possibilities are excluded by the universal incest taboos prohibiting marriage between parent and child and between siblings (see discussion in the chapter by Fadwa El Guindi), thus making the only structure consistent with the biological constraints on procreation and the cultural constraint on marriage between parent and child or between siblings expressed through the universal incest taboos be the one shown in Figure 3. This suggests that the incest taboo prohibitions on marriages between parent and child and between siblings may be universal for the reason discussed by Mary

19 In the United States, most states legally make the husband of a woman the presumed (legal) father of her child unless the presumed father has challenged that status on the grounds that the child was not the consequence of sexual intercourse between him and his wife.

20 With the exception of commoners among the Mosuo of China for whom marriage is not required for the child of a woman to be recognised as legitimate (Shih 2010), the common (though not exclusive) means across societies for a community to legitimate a female as bearer of children (that is for her children to be considered legitimate from the viewpoint of the community) is through marriage, however it may be locally construed (Malinowski 1927b, 1929, 1930; Gough 1959; Lehman 2011). 
Douglas (1966) regarding the food taboos of the Old Testament, namely that which would violate the understood order is made taboo in order to prevent it from being perceived as a possibility. ${ }^{21}$

The words naming the relations making up the Family Space, whether or not, in any particular instance, all of the positions defining the relations are instantiated and given content, are (in English) father, mother (or parent), son, daughter (or child), brother, sister (or sibling, a recent addition to the English vocabulary), and husband, wife (or spouse) (see Figure 4). These English words are also polysemic in the manner discussed by Scheffler since they refer to both genealogical and kin-term relations. For example, consider English 'mother'. Alone, the word 'mother' does not distinguish whether a pedigree relation, a genealogical relation or a kinterm relation is involved. Thus when an English speaker says: 'Mary is my mother', we do not know from that statement alone and without further elaboration, whether the speaker is saying that Mary begat speaker, or if speaker is saying that the kinship relation between Mary and speaker is that of mother, and reciprocally, child, even though Mary is not the begetter of speaker. It may be that Mary is being recognised as mother of speaker in the genealogical sense of a presumed begetter (even if she is not, factually, the biological mother), or it may be that she is being recognised as mother of speaker in a kin-term sense, in which case procreation need not be involved; for example, speaker was adopted by Mary. For clarity, as discussed in footnote 3 , I will italicise the word denoting a relation when it is being used in a kin-term sense; for example, mother, when the word 'mother' is being used in a kin-term sense.

21 The claim that the parent-child and sibling incest taboos are the consequence of the presumed Westermarck Effect (see, e.g. Wolf and Durham 2004; and Turner and Maryanski 2005) can be discounted on the grounds that there is (1) no unequivocal evidence supporting the assertion that persons raised together will have abhorrence (not just indifference) at the idea of having sex together (Leavitt 2005; Shor and Simchai 2009, 2012; Rantala and Marcinkowska 2011; El Guindi and Read 2012; Read 2014) and (2) under genetic equilibrium conditions, the frequency of phenotypes expressing deleterious effects due to the formation of homozygous genotypes for recessive, deleterious alleles is independent of the mating system (Read 2014), hence over evolutionary time scales sufficient to reach genetic equilibrium, inbreeding alone does not select for a particular mating type. The upsurge in deleterious effects that occurs with a shift to inbreeding from outbreeding is due to the change in mating type, not to inbred matings, per se. Under genetic equilibrium conditions, the rate of occurrence of homozygous genotypes for deleterious alleles tracks the mutation rate for the appearance of deleterious alleles, not the mating type. 


\section{From the Family Space to genealogical tracing}

Consider first the recursive process of genealogical tracing. Genealogical tracing, which we will only consider briefly, begins by cultural instantiation of the positions making up the Family Space. Under the presumption that procreation takes place in the context of marriage, there will be assigned both a female, call her $\mathrm{B}$, recognised as the mother and a male (call him C) recognised as the father of the individual A instantiated as self (see Figure 4). Let us refer to the former two individuals as the genealogical mother and the genealogical father, respectively, of person A instantiated as self. Genealogical tracing now proceeds recursively. We apply the same argument to each of B and C; e.g. for societal member B, there is understood to be person $\mathrm{D}$ who is the genealogical mother of $\mathrm{B}$ and person $\mathrm{E}$ who is understood to be the genealogical father of $\mathrm{B}$. We may now apply recursively the same argument to each person that has just been identified, and so on.

A

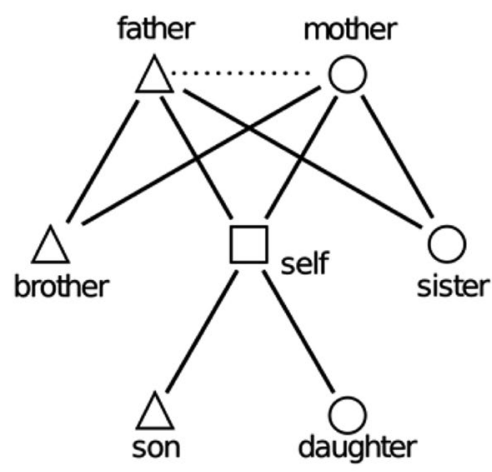

B

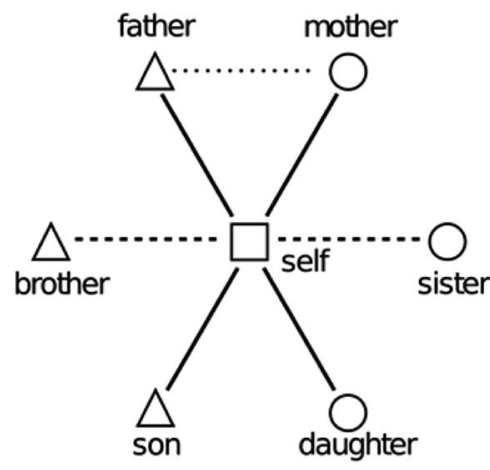

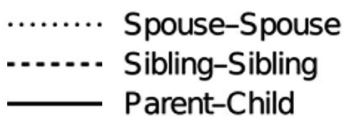

Figure 4. Graph of the Family Space with a self position for reference

There are two ways the sibling positions may be represented: (A) The sibling positions are related to the parent positions via the parent/child relation. (B) The sibling positions are related to the self position directly and to the parent position indirectly. In both (A) and (B), the spouse relation identifies the person instantiated as spouse to be the 'other (legitimate) parent'.

Source: Constructed by (c) Dwight Read. 
Similar arguments apply to the son and daughter reciprocal positions for the parental positions in the Family Space, except that there need not be a person culturally instantiated as son or daughter in an instance of a family, and similarly for the affinal positions of wife and husband. Note that while many authors have assumed, as discussed by Schneider (1984), that genealogical relations are biological, there is nothing in the recursive procedure for genealogical tracing that requires genealogical mother or genealogical father to be instantiated by biological mother or biological father, respectively, of the person instantiated as self. Thus, contrary to Schneider's assumption, kinship may involve genealogical relations without, at the same time, presuming that these are necessarily biological relations. To put it simply, a genealogy based on genealogical parent and genealogical child need not be a pedigree. Nonetheless, there is still a biological substrate due to the fact that the status of, for example, motherhood in the Family Space is modelled on biological mother and the behaviours presumed to be associated with being a biological mother.

\section{From the Family Space to a kinship terminology}

Now consider how kin-term relations can be generated from the relations in the Family Space through the kin-term product. I will not provide a full account here (for a more detailed account see, e.g. Read 2000, 2007; Leaf and Read 2012; Read, Fischer and Lehman 2014). Instead, I shall limit myself to deriving only what is needed to resolve the extension problem through showing how the extension from close to more distant genealogical relations follows directly from the way kin-term relations are generated from the relations in the Family Space. The latter will also provide the basis for making predictions of the genealogical relations corresponding to a kin-term relation. Though I will illustrate the argument using the American/English terminology, it applies equally to other terminologies (Read 2007; Leaf and Read 2012). 


\section{Generation of an ascending kin-term structure; predicted categories of genealogical relations}

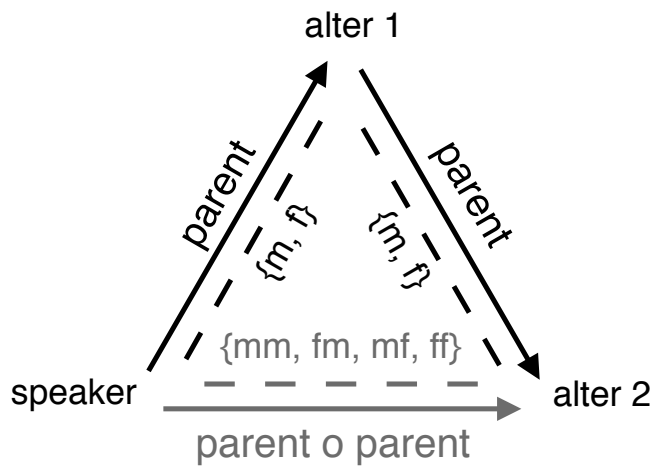

Figure 5. Kin-term product of parent with itself generates a new kin-term relation, parent o parent, given the name grandparent

The kin types subsumed under the kin terms corresponding to the black arrows are marked with a black dashed line. The predicted kin types (in grey) associated with the generated kin term grandparent $=$ parent o parent are determined by taking the product of the sets of kin types subsumed by the kin terms in the kin-term product parent o parent: $\{m, f\} \times\{m, f\}$ $=\{\mathrm{mm}, \mathrm{fm}, \mathrm{mf}, \mathrm{ff}\}$.

Source: Constructed by @ D Dwight Read.

Let us begin with self and the kin terms corresponding to the non sexmarked, primary kinship relations of the American/English terminology, namely the primary kin terms parent, child, and spouse. ${ }^{22}$ Start with the ascending primary term, parent, and form the kin-term product parent o parent determined by alter 1 referring to alter 2 by parent and speaker referring to alter 1 by parent (see Figure 5). Then parent $\mathrm{o}$ parent will be the generated kinship relation between speaker and alter 2 . This generated relation has the name grandparent, which indicates that the kin-term

22 The choice of non sex-marked primary relations stems from the fact that all of the sex-marked terms in the American/English terminology come in pairs for which a kin-term product that terminates at, or begins with, one term of the pair is matched precisely by a kin-term product that terminates at, or begins with, the other term of that pair. For example, for the pair grandmother, grandfather, each kin-term product with one term of the pair, such as son o grandmother = uncle, is matched by a corresponding kin-term product, in this case son o grandfather = uncle, with the other term of the pair. For products in the other direction, father o mother = grandfather = father o father is matched by mother o mother = grandmother = mother o father. Thus the sex-marked primary terms can be considered to be the bifurcation of neutral terms into male and female marked terms. Were we to use the sex-marked (rather than the neutral) primary terms as generators, we would end up with a generative account that requires introducing numerous ad hoc equations solely to 'force' the generated structure to match the observed structure, whereas with the neutral primary terms, no ad hoc equations are needed. 
product, parent o parent, determines a kinship relation recognised as such by culture bearers. This also establishes the meaning of the kin term grandparent to be the name for the generated kinship relation, parent $\mathrm{o}$ parent. Note that constructing new kinship relations from primary kin terms through the kin-term product parallels the process of generating new symbolic numbers from the symbolic primary counting number 1 through the binary operation ' + '; that is, from the primary symbolic number 1, construct the new symbolic number $1+1$ and give it the name two and symbolise it by '2'. From the symbolic number 2, construct the new symbolic number $1+2$ and give it the name three and symbolise it by ' 3 ', and so on.

The kin-term product also predicts a category of genealogical relations corresponding to a kin term such as grandfather generated as the kinterm product of primary kin terms, or more generally, a category of genealogical relations corresponding to a kin term that is the kin-term product of a primary kin term with an already generated kin term. (In the following discussion, for succinctness in referring to the members of a genealogical category, I will use kin-type notation, using lower case letters, for the genealogical relations: for example, $f, m, s$, and $d$ will be the kin types corresponding to genealogical father, mother, son and daughter, respectively.) The predicted category is determined by computing, in the order corresponding to that of the kin terms in the product of the kin terms generating the kin term in question, all possible products of kin types, one from each category of genealogical relations corresponding to each primary kin term in the kin-term product generating the kin-term relation, with each product formed in the order of the kin terms in the kin-term product. Thus for grandparent $=$ parent $\mathrm{o}$ parent, we form the category of predicted genealogical relations for grandparent by computing $\{\mathrm{m}, \mathrm{f}\} \times\{\mathrm{m}, \mathrm{f}\}=\{\mathrm{mm}, \mathrm{fm}, \mathrm{mf}, \mathrm{ff}\}$, using the formal brace notation for sets, since the category of kin types corresponding to the primary kin term, parent, is, from the Family Space, the category consisting of the kin types $\mathrm{m}$ and $\mathrm{f}$ and can be denoted by the set $\{\mathrm{m}, \mathrm{f}\}$ (see Figure 5 , dashed lines). ${ }^{23}$ The predicted set of genealogical referents, $\{\mathrm{mm}, \mathrm{fm}, \mathrm{mf}$, $\mathrm{ff}$, is precisely the actual set of genealogical referents for the kin term grandparent.

23 I use the convention that kin-term products are written from right to left so that a kin-term product may be read directly as an English phrase by substituting 'of' for the kin-term product symbol 'o'. Thus daughter o aunt may be read 'daughter of aunt', and this corresponds to alter 1 referring to alter 2 by the kin term daughter and speaker referring to alter 1 by the kin term aunt. In contrast, products of 
We continue the construction process for kin terms by forming, recursively, all possible products of the primary kin term parent with each term that is generated, and giving each new product a name when it generates a kin-term relation recognised as such by culture bearers. Thus, following this procedure, we next introduce great-grandparent as the name for the kin term corresponding to the kin-term product parent o grandparent since the kin-term relation corresponding to this kin-term product is recognised as such by culture bearers; that is great-grandparent is the kin term that speaker properly uses to refer to alter 2 when alter 1 refers to alter 2 as parent and speaker refers to alter 1 as grandparent. To form the predicted set of genealogical referents corresponding to the kin term great-grandparent $=$ parent $\mathrm{o}$ grandparent , we compute the product of the categories of kin types corresponding to parent and grandparent, respectively, and obtain $\{\mathrm{m}, \mathrm{f}\} \times\{\mathrm{mm}, \mathrm{fm}, \mathrm{mf}, \mathrm{ff}\}=\{\mathrm{mmm}, \mathrm{fmm}, \mathrm{mfm}$, $\mathrm{ffm}, \mathrm{mmf}, \mathrm{fmf}, \mathrm{mff}, \mathrm{fff}\}$ as the set of genealogical referents for the kin term great-grandparent. Next, we introduce great-great-grandparent as the name for the kin-term relation given by the kin-term product parent $\mathrm{o}$ great-grandparent (since this kin-term product is recognised as a kin-term relation by culture bearers) and determine the set of genealogical referents for the kin term great-great-grandparent by computing $\{\mathrm{m}, \mathrm{f}\} \times\{\mathrm{mmm}$, fmm, $\mathrm{mfm}, \mathrm{ffm}, \mathrm{mmf}, \mathrm{fmf}, \mathrm{mff}, \mathrm{fff}\}=\{\mathrm{mmmm}, \mathrm{fmmm}, \ldots, \mathrm{mfff}, \mathrm{ffff}\}$, which is precisely the category of genealogical referents for the kin term great-great-grandparent, and so on. For the American/English terminology, this process continues indefinitely, hence a new kin term is included for each additional product with the primary kin term parent.

In other terminologies, the sequence of new kin terms does not continue indefinitely and the kin-term products eventually become reflexive, or are not considered to determine a kinship relation, or make a closed

\footnotetext{
kin types are written from left to right so that a kin-type product string can be read using the possessive form for each kin type in the product except the last one; thus 'fm' is read as the genealogical relation f's m, or 'father's mother', With this convention, the product of the categories of kin types formed by taking the product of the category of kin types corresponding to each term in the kin-term product becomes reversed from that of the kin-term products. For example, the kin-term product father o mother (read father of mother) corresponds to the kin-type category product $\{\mathrm{f}\} \times\{\mathrm{m}\}=\{\mathrm{mf}\}$ (read 'the category of kin types whose only member is m's $\mathrm{f}$, or $\mathrm{mf}$, for short'). That is, the category in question is formed by first taking a kin type from the first category in the product of categories and then taking the kintype product of it with a kin type from the second category, with the order of the kin-type products reversed from that of the kin-term products. Hence the predicted genealogical relations for the kin term grandfather = parent o parent (read, using sex-marked kin terms in place of parent, 'mother or father of mother or father') is the category of kin types given by $\{\mathrm{mm}, \mathrm{fm}, \mathrm{mf}$, $\mathrm{ff}\}$, where the kin-type products are read in the indicated order: 'm's $m$, f's $m$, m's $f$, or f's $f$ '.
} 
loop as occurs when the kin-term product of a primary ascendant kin term with the most ascendant kin term in the terminology is equated with the most descendant kin term, as happens in the terminology for the Kariera, a hunter-gatherer group in Western Australia (RadcliffeBrown 1913; see discussion in Leaf and Read 2012). Reflexivity can be represented structurally by an equation that defines the next product in the sequence of products to be equal to the current product. Thus, in the Tongan terminology with primary ascending male-marked kin term tamai ('father'), we generate the sequence of ascending kin terms given by: tamai, tamai o tamai = kui ('grandparent'), and tamai o kui = kui (see Bennardo and Read 2007). The last equation indicates that kui is used in all ascending generations from the second generation upwards.

Here, corresponding to tamai o tamai = kui, we have the predicted category of genealogical relations given by $\{\mathrm{f}\} \times\{\mathrm{f}\}=\{\mathrm{ff}$, which obviously is not the full set of genealogical relations for the kin term kui. We also need to consider other products of primary ascending terms equal to kui. For the Tongan terminology, this includes kin-term products using the primary female-marked kin term fa'e ('mother') as well. We find that $k u i$ is also generated by fáe o fáe = kui, fáe o tamai =kui, and tamai o $f a{ }^{\prime} e=k u i$, which implies that the kin-type products $\{\mathrm{m}\} \times\{\mathrm{m}\}=\{\mathrm{mm}\}$, $\{\mathrm{m}\} \times\{\mathrm{f}\}=\{\mathrm{fm}\}$ and $\{\mathrm{f}\} \times\{\mathrm{m}\}=\{\mathrm{mf}\}$ are also referents of the kin term $k u i$, hence $\mathrm{ff}, \mathrm{mm}, \mathrm{fm}$, and $\mathrm{mf}$ are included in the predicted category of kin types corresponding to kui. In other words, included as genealogical referents of a kin term are the kin-type products corresponding to any kin-term product that equals (that is, is reducible to, using the structural equations) the kin term in question. We will use this property below to show how the extension problem is resolved through the generative logic for classificatory terminologies. Before doing so, we need to continue further with this overview of the process by which a kinship terminology is generated from primary kin terms.

Structural equations are crucial to this generative process as they can be used to express cultural concepts regarding kinship relations embedded within the kinship terminology. Whereas English speakers consider kinship relations to extend indefinitely in an ascending direction and are labelled with a new kin term in each generation, Tongans consider, as noted above, each of these kinship relations to be marked with a new kin term only up to the +2 generation, with the kin term in the +2 generation repeated in subsequent generations. This reflexive property may be denoted, as indicated above, by introducing the structural equations tamai o $k u i=k u i$ 
and $f a^{\prime} e \mathrm{o} k u i=k u i$ into the generative process for the Tongan terminology. Note that structural equations like this that express differences between English and Tongan speakers in their respective ideas about kinship relations are taken as axiomatic in the formal representation. The reason for differences like this among kinship terminologies is an interesting question in its own right whose (as yet uncertain) answer lies outside the immediate purview of the generative logic for a kinship terminology or that of any account of kinship terminologies for that matter.

\section{Generation of a descending kin-term structure; predicted categories of genealogical relations}

Typically (see discussions in Read 2007; Leaf and Read 2012), the generation of a kinship terminology continues by next generating a descending structure isomorphic to the ascending structure that has just been generated. The isomorphic descending structure is formed by introducing a (generally distinct) primary descending term for each primary ascending term used to generate the ascending structure. ${ }^{24}$ The primary descending term corresponding to a primary ascending term will be said to be structurally isomorphic to that ascending term, and viceversa. For the American/English terminology, the structurally isomorphic primary descending term corresponding to the (single) primary ascending term parent will be the primary term child. For the American/English terminology, the descending structure isomorphic to the ascending structure with terms parent, grandparent $(=$ parent o parent $)$, greatgrandparent $(=$ parent $\mathrm{o}$ grandparent $) \ldots$ will be the isomorphic structure with terms child, grandchild (= child o child), great-grandchild (= child o grandchild) ... In addition, the isomorphic version of any structural equation that is part of the ascending structure will be included in the descending structure. For the Tongan terminology, an isomorphic copy of the ascending structural equation tamai o kui = kui, (read: 'father' of 'grandfather' is 'grandfather'), namely (for a male speaker) foha o mokopuna = mokopuna, where foha ('son') is structurally isomorphic to tamai ('father') and mokopuna ('grandson') = foha o foha, is included in the descending structure. The predicted categories of kin types corresponding to the descending kin terms are then generated in a manner analogous to the way the predicted categories of kin types are generated for the ascending kin terms.

24 For the English terminology, there is but one primary ascending term, namely parent, but in other terminologies such as the Tongan terminology, more than a single ascending primary term is used to generate the ascending structure (see Bennardo and Read 2007 for details). 


\section{Reciprocal kin terms}

Not yet included in the construction is a structural criterion that defines the structurally isomorphic English kin terms, parent and child, introduced, respectively, in the generation of the ascending and the descending structures, to be reciprocal terms and not just isomorphic corresponding kin terms. With regard to usage, if speaker refers to alter by the kin term $\mathrm{L}$ (e.g. child), then the reciprocal term for $\mathrm{L}$ is the term $\mathrm{K}$ (i.e. parent) that alter properly uses for speaker. In addition, when considering reciprocal kin terms, the sex of speaker may need to be taken into account, as well as whether the reciprocal is determined within just the domain of consanguineal relations, or in the domain of both consanguineal and affinal relations, which depends on whether affinal relations have yet been introduced in the construction process.

The definition of reciprocal terms determined through usage can be transformed into a structural equation. To do this, note that when generating a kinship terminology by first generating a structure of ascending terms and next an isomorphic structure of descending terms, the genealogical references for the kin terms constructed so far will just be consanguineal genealogical relations since affinal kin terms have not yet been introduced, hence we will identify the structural equation that defines kin terms $\mathrm{K}$ and $\mathrm{L}$ to be reciprocal terms in the domain of consanguineal relations.

The usage definition for $\mathrm{K}$ and $\mathrm{L}$ to be reciprocal kin terms can be restated using the kin-term product. For example, if $\mathrm{L}=$ child and $\mathrm{K}=$ parent, suppose alter 1 refers to alter 2 as parent and speaker refers to alter 1 as child. Then since child and parent are reciprocal terms and we are only considering (so far) consanguineal genealogical relations for speaker, alter 2 must be speaker. We now ask: What expression does speaker use for alter 2 = speaker? and the answer, obviously, is myself (or self, for short). Thus, parent $\mathrm{o}$ child $=$ self is the kin-term equation corresponding to the fact that parent and child are reciprocal kin terms. Note that if we reverse child and parent in this equation and alter 1 refers to alter 2 as child and speaker refers to alter 1 as parent, then alter 2 need not be speaker and if alter 2 is not speaker, then speaker refers to alter 2 as sibling. Thus, child o parent $=$ sibling for English speakers. Observe that the predicted kin-type referents for sibling derived from the kin-term equation child o parent $=$ sibling are given by $\{\mathrm{s}, \mathrm{d}\} \times\{\mathrm{f}, \mathrm{m}\}=\{\mathrm{fs}, \mathrm{ms}, \mathrm{fd}, \mathrm{md}\}=\{\mathrm{b}, \mathrm{z}\}$, where $\mathrm{b}(\mathrm{z})$ is the genealogical relation standing for fs or $\mathrm{ms}$ ( $\mathrm{fd}$ or $\mathrm{md}$ ). Thus, 
the kin-term product parent $\mathrm{o}$ child $=$ self defines parent and child to be reciprocal kin terms, whereas the kin-term product child o parent defines a new kin-term relation, sibling, with predicted genealogical referents $\{b$, z\}. In algebraic terms, we have also established that the kin-term product is not commutative for the American/English kinship terminology since parent $\mathrm{o}$ child $\neq$ child $\mathrm{o}$ parent.

The form of the structural equation, parent $\mathrm{o}$ child $=$ self, that defines parent and child to be reciprocal kin terms is not specific to the American/English terminology or to these primary kin terms, but is a general property of kinship terminologies and primary kin terms. The structural form of the equation, parent $\mathrm{o}$ child $=$ self, defining child to be the reciprocal of parent is (in words): ascending primary term of descending primary term is self, where the descending primary term is structurally isomorphic to the ascending primary term. In general, if $\mathrm{K}$ and $\mathrm{L}$ are structurally isomorphic primary ascending and descending kin terms, respectively, and if alter 1 refers to alter 2 by $\mathrm{K}$ and speaker refers to alter 1 by $\mathrm{L}$, then the structural equation $\mathrm{Ko} \mathrm{L}=$ self defines $\mathrm{K}$ and $\mathrm{L}$ to be reciprocal kin terms. In some cases, such as with the primary kin term spouse that expresses the affinal relation for English speakers, the kin term is self-reciprocal, meaning that we have, for the kin term spouse, the structural equation spouse o spouse $=$ self. A selfreciprocal primary kin term is neither an ascending nor a descending kin term, just as 0 is neither a positive nor a negative number.

We may structurally define the reciprocal kin term for a nonprimary kin term $\mathrm{K}$ as follows. Since $\mathrm{K}$ is not a primary kin term, it is generated from primary kin terms, so we may write $\mathrm{K}$ as a product of primary kin terms, say $\mathrm{K}=\mathrm{P}_{1} \circ \mathrm{P}_{2} \circ \ldots \circ \mathrm{P}_{\mathrm{n}}$, where each $\mathrm{P}_{\mathrm{i}}$ is a primary kin term and the same primary kin term may appear more than once in a sequence of kinterm products of primary terms. The reciprocal kin term for $\mathrm{K}$, which we will denote by $\mathrm{K}^{\mathrm{r}}$, is given by the kin-term product of the reciprocal terms for the primary kin terms but in reverse order: $\mathrm{K}^{\mathrm{r}}=\mathrm{P}_{n}{ }^{\mathrm{r}} \mathrm{O} \mathrm{P}_{\mathrm{n}-1}{ }^{\mathrm{r}} \mathrm{O}$ ... o $\mathrm{P}_{1}^{\mathrm{r}}$, where $\mathrm{P}_{\mathrm{i}}^{\mathrm{r}}$ denotes the reciprocal kin term for the primary kin term $\mathrm{P}_{\mathrm{i}}$. For example, from sibling = child o parent, we determine that the reciprocal of sibling is given by sibling ${ }^{r}=$ parent $^{r} \mathrm{o}$ child $^{\mathrm{r}}$; that is by the kin-term product of the reciprocal of parent $(=$ child $)$ and the reciprocal of child (= parent), in that order, so the reciprocal of sibling is given by child o parent $=$ sibling, hence sibling must be a self-reciprocal kin term and so is neither an ascending nor a descending kin term. 


\section{American/English Kinship Terminology}

\section{Primary Kin Terms}

Self, Parent, Child, Spouse

\section{Structural Equations}

Reciprocal Definition Equation for Child and Parent

Child o Parent $=$ Self

Spouse Definition Equation

Spouse o Spouse $=$ Self

Affinal Equations

Spouse 0 Parent $=$ Parent

Spouse o Child o Parent $=$ Child o Parent o Spouse

Affinal Restriction Equations

Parent o Spouse o Child $=0$

Parent o Parent o Spouse $=0$

\section{Structural Rules}

Sex Marking of Kin Terms

Kin term K is sex marked if Spouse o $\mathrm{K}$ is a kin term or Spouse o $\mathrm{Kr}$ is

a kin term, where $\mathrm{Kr}$ is the reciprocal term for $\mathrm{K}$

\section{Generated Kinship Terminology Structure}

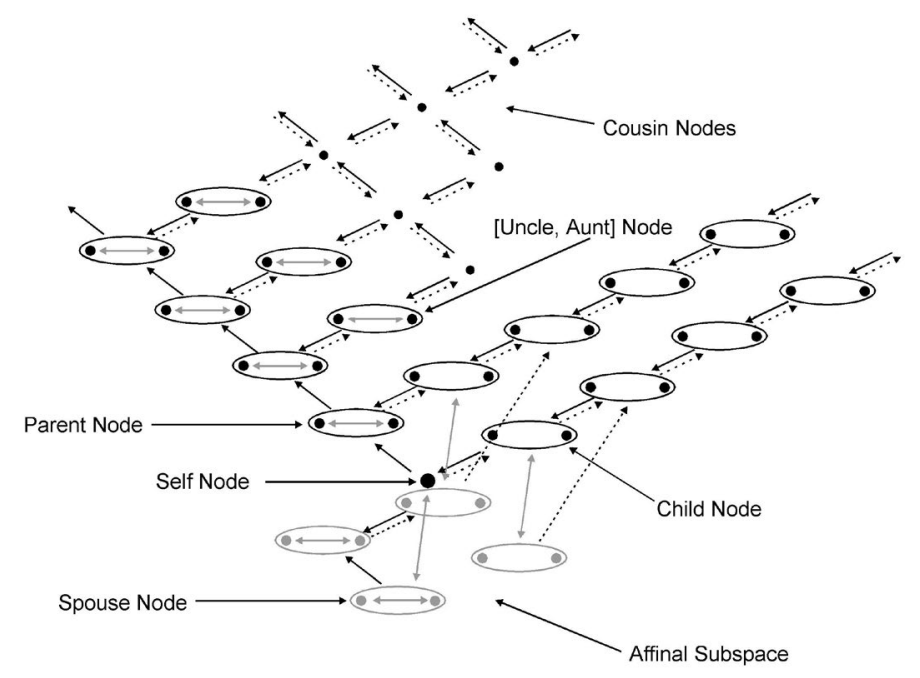

Figure 6. Primary kin terms and structural equations for generating the American/English terminology

Bottom graph: Generated structure isomorphic to the kin-term map for the American/ English terminology (see Figure 2a).

Source: Constructed by @ Dwight Read. 
Though sibling and spouse are both self-reciprocal, sibling differs structurally from spouse due to the (axiomatic) kin-term product equation spouse o parent $=$ parent (see Read 2007; Leaf and Read 2012) corresponding to the cultural knowledge of culture bearers that 'spouse of parent is parent', whereas sibling o parent defines a new kin term for English speakers. For this latter kin-term product, we have for its name and using sexmarked kin terms, either sibling o parent $=$ aunt or sibling o parent $=$ uncle. These examples show how, through the generative logic for the kinship terminology, we can account for properties of the kin terms making up a kinship terminology and the way kin terms in this terminology are structurally linked to one another.

\section{Generation of the complete American/English kinship terminology}

We will not go through the entire process of generating the American/ English terminology through kin-term products, a process that uses, as shown above, the set $\mathrm{G}$ of generating terms given by $\mathrm{G}=\{$ self, parent, child, spouse\}. Interested readers can consult Read (1984, 2000, 2007); Read and Behrens (1990); Bennardo and Read (2007) or Leaf and Read (2012) for details. We only present here the final set of structural equations used to generate the American/English kinship terminology and the structure generated from these structural equations (see Figure 6). As can be seen from Figure 6, the structural equations for the American/ English terminology are culturally salient and express properties of the terminology familiar to the users of the terminology. This is no coincidence, but stems from the kinship terminology being generated through structural properties (primary terms and structural equations) that are culturally salient.

The generated structure can be shown to be isomorphic to the empirically derived structure for the American/English kinship terminology shown in Figure 2a, hence we now have an explanation for the structural form of the American/English kinship terminology by reference to the cultural knowledge shown in Figure 6. Other terminologies will differ from the American/English kinship terminology by different choices of primary terms used to generate the terminology and/or in the equations that express structural properties embedded in the kinship terminology. 


\section{Two culturally salient definitions for sibling in the Family Space}

One additional property of the Family Space is needed before we can account for the extension of the referents of kin terms from closer to more distant genealogical relations. Structurally, there are two ways that a sibling may be defined: (A) speaker's sibling is the child of speaker's parent other than speaker and (B) individuals $A$ and $B$ are siblings when the parents of A are also the parents of B (see Figure 4). Empirical justification for these two ways to conceptualise sibling comes from ethnographic observations regarding the importance of the sibling relation when sibling is conceptualised through shared parents, as occurs, for example, with the Kaluli and the Tangu groups of New Guinea (see also Knight 2011). According to Edward Schieffelin, when the Kaluli work out kin relations:

[They] frequently invoke a sibling relationship as the link that explains the application of a term - 'I call him brother because my father calls his father brother' ... [T] he sibling relationship takes precedence over descent [parent-child links] whenever the principles are in conflict [emphasis in original] (1976: 54-55).

Likewise, Kenelm Burridge notes the Tangu consider that:

[S]iblingship is the determinant that descent [parent-child links] might have been expected to be ... descent was probably always calculated from siblingship $\ldots$ and siblingship rather than descent always provided the definitive norms of social behavior (1959-1960: 128, 130).

R.R. Nayacakalou, an indigenous Fijian ethnographer, makes a similar comment for the Fijian classificatory terminology: '[I]f A is a classificatory father to $\mathrm{B}$, and $\mathrm{C}$ is also a classificatory father to $\mathrm{B}$, then $\mathrm{A}$ and $\mathrm{C}$ are classificatory brothers, even if no genealogical tie can be traced between them' (1955: 48).

He also identifies conceptualising siblings in Fiji through what he calls the 'principle ... of common parentage, which binds together the members of a sibling group' (ibid.: 46) (see Figure 4(B)). German Dziebel finds that both definitions (A) and (B) of sibling are needed to accommodate differences among terminologies regarding sibling kin-term relations. He then links siblings defined through common parents with classificatory terminologies: '[I]f alternatively Ego prefers to think that he shares ... common ascent with his siblings, 0 generation terminology will be Bifurcate Merging [i.e. classificatory]' (2007: 233). 
These two ways of conceptualising sibling shown in Figure 4 correspond to a compound kin term (Figure $4(\mathrm{~A})$ ) versus a primary generating kin term (Figure 4(B)). Definition (A) implies that the kin term translated as 'sibling' is a compound kin term: 'sibling' = 'child' o 'parent'. Definition (B) implies that 'sibling' is a primary generating kin term. ${ }^{25}$

\section{Generating a classificatory terminology}

We next consider the structural properties introduced logically when 'sibling' is one of the primary generating terms. As we will see, the addition of 'sibling' as a generating term leads to classificatory terminologies. For simplicity of notation in the following, we will use capital letters $F, M, S$, $\mathrm{D}, \mathrm{B}, \mathrm{B}+, \mathrm{B}-, \mathrm{Z}, \mathrm{Z}_{+}, \mathrm{Z}$ - to denote the kin terms for the father, mother, son, daughter, brother, older brother, younger brother, and sister, older sister, and younger sister relations, respectively, in the Family Space. We begin by generating male marked kin terms (or equivalently, we begin by generating female marked kin terms). ${ }^{26}$ Let $\mathbf{A}=\{$ male self, $\mathrm{F}, \mathrm{B}+\}$ be the

25 Keen (1985) incorrectly assumes sibling must be a second-order kin relationship; that is, sibling, as a kin-term concept, must be conceptualised through the kin-term product, 'child' of 'parent.' This ignores the ethnographic evidence, a small part of which has been presented here, showing that, for many groups, sibling is conceptualised as a first-order kin relationship (to use Keen's vocabulary), and hence is a primary generating term. Wierzbicka (2016) makes a related error by assuming that the prerequisite for having a 'sibling' kin term is having a linguistic term for a sibling concept in which sibling is 'undifferentiated in gender and relative age' (ibid.: 412). Since such a sibling concept is not universally given linguistic recognition, she argues that sibling is not a universal concept. Her assertion, however, confounds sibling as a structural relation in the Family Space that may, on the one hand, be incorporated into a system of kin-term relations expressed through the kin terms making up a kinship terminology in different ways (see Read 2011, 2014 for examples), with, on the other hand, sibling as a genealogical relation undifferentiated in gender or by relative age. 'Sibling' from the perspective of the conceptual system of kin-term relations making up a KTS expressed through a kinship terminology, and 'sibling', from the perspective of the conceptual system of genealogical relations making up what Lehman and Witz (1974) referred to as a PGS, are not one and the same thing. In her example of Kyardild kin terms, Wierzbicka provides definitions for their 'sibling' terms that do not require the use of the technical construct, ego, or the kin-type, sibling; that is, her definitions reinforce the incorrectness of the ontology going necessarily from procreation to genealogy to kinship terms. For the Kyardild sibling kin term wakatha, she gives the definition (contra Keen's assumption): 'a man can say about a woman "this is my wakatha" if he can think about her like this: "her mother is my mother, her father is my father" - but this just defines one of two structural ways the sibling relation can be part of the Family Space (see Figure 4), each of which can be defined (as must be the case) without using concepts that depend upon already having the KTS or the PGS in place. In other words, her argument validates taking the Family Space to be axiomatic. Further, since she has provided a definition of their kin term, wakatha, that does not require reference to a KTS or to the PGS, wakatha is a linguistically recognised primary kin-term concept, hence a generating term for their kinship terminology.

26 The rationale for first generating structures of male marked, or female marked, terms has been discussed extensively, and illustrated with the Tongan, the Kariera, the Trobriand and the Dravidian terminologies in: Read and Behrens 1990; Bennardo and Read 2007; Read 2010a; Leaf and Read 2012. 
generating set for the ascending, male-marked kinship terms and include both the structural equation $\mathrm{F}$ o $\mathrm{B}+=\mathrm{F}$ ('father' of 'older brother' is 'father'), in agreement with the second definition for sibling given above, and the structural equation $\mathrm{B}+\mathrm{o} \mathrm{B}+=\mathrm{B}+$ ('older brother' of 'older brother' is 'older brother') that structurally identifies $\mathrm{B}+$ as a sibling kin term in the ascending structure.

Typically, classificatory terminologies become reflexive beyond the +2 generation, so we also include the equation $\mathrm{F}$ o $(\mathrm{F}$ o F $)=\mathrm{F}$ o F, or more succinctly, $\mathrm{F}^{3}=\mathrm{F}^{2}$. The distinct kin terms we generate from $\mathrm{A}$ and the structural equations $\mathrm{Fo} B+=\mathrm{F}, \mathrm{B}+\mathrm{o} \mathrm{B}+=\mathrm{B}+$ and $\mathrm{F}^{3}=\mathrm{F}^{2}$ are:

$\mathrm{F}, \mathrm{F}^{2}, \mathrm{~B}+, \mathrm{B}+\mathrm{o} \mathrm{F}$, and $\mathrm{B}+\mathrm{o} \mathrm{F}^{2}$ ('father', 'grandfather', 'older brother', 'older brother' of 'father', and 'older brother' of 'grandfather', respectively).

Note that at this stage in the construction, $\mathrm{B}+\mathrm{o} F$ ('older brother' of 'father') and B+o $\mathrm{F}^{2}$ ('older brother' of 'grandfather') are each distinct kin-term relations since no structural equations that would reduce these kin-term products to a simpler form have yet been introduced.

Next, we generate an isomorphic structure of descending terms using the generating set $\mathrm{D}=\{$ male self, $\mathrm{S}, \mathrm{B}-\}$. Then we introduce the structural equations $\mathrm{F}$ o $\mathrm{S}=$ male self and $\mathrm{B}+\mathrm{o} \mathrm{B}-=$ male self $=\mathrm{B}-\mathrm{o} \mathrm{B}+$ to define $\mathrm{F}$ and $S$ as a pair of reciprocal kin terms and $\mathrm{B}+$ and $\mathrm{B}$ - as a second pair of reciprocal kin terms. Since the descending structure will be isomorphic to the ascending structure, we also include the structural equations $S^{3}=S^{2}$ and $\mathrm{S}$ o $\mathrm{B}-=\mathrm{S}$ that are isomorphic to $\mathrm{F}^{3}=\mathrm{F}^{2}$ and $\mathrm{F}$ o $\mathrm{B}+=\mathrm{F}$, respectively. Note that the equations isomorphic to the two equations $\mathrm{B}+\mathrm{o} \mathrm{B}-=$ male self $=\mathrm{B}-\mathrm{o} \mathrm{B}+$ are just these two equations again, so no new equations would be introduced through including the isomorphic forms of these two equations.

One other general property of kinship terminologies needs to be introduced, namely that the reciprocal version of a structural equation is also a structural equation for the terminology (see Scheffler 1986), which follows from the isomorphism between the ascending and the descending structures. Thus, from the equation $S$ o B- $=S$, we include the reciprocal structural equation $B-{ }^{r}$ o $S^{r}=S^{r}$, which corresponds to $B+o F=F$. This last equation introduces the structural equation, 'older brother' of 'father' = 'father'. Further, from B+o F = F, it follows that B-o B+o F = B-o F, and since $\mathrm{B}-\mathrm{o} \mathrm{B}+=$ male self, we have: 


$$
\begin{gathered}
\mathrm{B}-\mathrm{o} \mathrm{F}=\mathrm{B}-\mathrm{o} \mathrm{B}+\mathrm{o} \mathrm{F} \\
=\text { male self } \mathrm{o} \mathrm{F} .
\end{gathered}
$$

Since male self $\mathrm{o} F=\mathrm{F},{ }^{27}$ it follows that $\mathrm{B}-\mathrm{o} \mathrm{F}=\mathrm{F}$, and so $\mathrm{B}$ o $\mathrm{F}=\mathrm{F}$, where $\mathrm{B}$ is either $\mathrm{B}+$ or B-; that is 'brother' of 'father' is 'father'. From the equation $\mathrm{B}$ o $\mathrm{F}=\mathrm{F}$, it follows that the reciprocal of this equation, namely $\mathrm{F}^{\mathrm{r}}$ o $\mathrm{B}^{\mathrm{r}}=\mathrm{F}^{\mathrm{r}}$; i.e. $\mathrm{S}$ o $\mathrm{B}=\mathrm{S}$, is also a structural equation for the terminology. Thus, the structural equations, $\mathrm{B}$ o $\mathrm{F}=\mathrm{F}$ ('brother' of 'father' is 'father') and $S$ o $B=S$ ('son' of 'brother' is 'son'), fundamental to distinguishing classificatory terminologies as a distinct class of terminologies, are the logical consequence of generating a kinship terminology when a sibling term is also a generating term. Hence Morgan's distinction between descriptive and classificatory terminologies can now be expressed structurally through whether the terminology has 'sibling' as a primary, generating term (classificatory terminologies) or whether 'sibling' is a compound kin term of the form 'child' of 'parent' is 'sibling' (descriptive terminologies).

For our purposes here, I need not carry out the generation of a classificatory terminology any further. Interested readers can consult Bennardo and Read (2007) for the generation of the Tongan classificatory kinship terminology, Read (2010b) for the generation of a Dravidian terminology, and Leaf and Read (2012) for the generation of the Kariera kinship terminology for examples of generating a classificatory terminology. I now assume that we have done the rest of the construction and turn to resolving the extension problem, using the classificatory kin term 'father'. The means for so doing with the kin term 'father' will also serve as a canonical procedure for showing how the extension problem is resolved, in general, through the logical consequences of having a sibling term as one of the generating terms. I carry out this demonstration in three parts.

27 The kin-term product male selfo $\mathrm{F}$ means alter 1 refers to alter 2 as $\mathrm{F}$ and male speaker refers to alter 1 as male self. The kin-term product, male self $\mathrm{o} F$, will be equal to the kin term $M$ that speaker (properly) uses for alter 2. Since speaker refers to alter 1 as male self, then alter 1 is speaker, hence the fact that alter 1 refers to alter 2 as $F$ means that speaker refers to alter 2 as $F$, thus male selfo $F=F$. The equation, $\mathrm{F}$ o male self, may be shown in a similar manner. In general, the term, self will be an identity element for the kin-term product; that is, for any kin term $K$, self $\mathrm{o} K=\mathrm{K}=\mathrm{K}$ o self. The sex-marked terms male self and female self will be identity elements for kin-term products of kin terms with the same-sex marking, as shown above for male self and F. 


\section{Resolution of the extension problem}

\section{Part 1: Primary kin types for the lineal kin terms}

I begin by noting that the generating term, F, generates the lineal sequence of ascending kin terms given by $\mathrm{F}, \mathrm{F}^{2}, \mathrm{~F}^{3}=\mathrm{F}^{2}$, with predicted, corresponding categories of kin types $\{\mathrm{f}\}$ and $\{\mathrm{ff}, \mathrm{fff}, \ldots\}$ for $F$ and $\mathrm{F}^{2}$, respectively. Let $S$ be the descending generating term isomorphic to $F$. The term $S$ generates the lineal sequence of descending kin terms, $S, S^{2}$, and $S^{3}=S^{2}$, with $\{s\}$ and $\{s s$, sss, ... $\}$ as the predicted genealogical categories of kin types corresponding to $S$ and $S^{2}$, respectively. This part of the construction structurally subsumes the reduction made by Scheffler and Lounsbury of the genealogical categories corresponding to lineal terms to their primary (lineal) kin types, except whereas they needed to rationalise the reason for so doing, the generation of a classificatory terminology already provides the underlying structural basis for distinguishing the primary kin types for the lineal kin terms (see also the discussion of this topic by Shapiro Chapter 1).

\section{Part 2: Extension of 'father' to father's brother}

The structural equations $\mathrm{B}+\mathrm{o} F=\mathrm{F}=\mathrm{B}-\mathrm{o} \mathrm{F}$, with corresponding kin-type products:

$$
\begin{aligned}
\{\mathrm{b}+\} & \times\{\mathrm{f}\}=\{\mathrm{b}-\} \times\{\mathrm{f}\} \\
& =\{\mathrm{fb}-, \mathrm{fb}+\} \\
& =\{\mathrm{fb}\},
\end{aligned}
$$

extend the category of genealogical kin types corresponding to 'father' to include $\mathrm{fb}$, where $\mathrm{b}$ refers either to genealogical older brother, $\mathrm{b}+$, or genealogical younger brother, b-. Similar arguments may be made for other kin terms expressed as products of primary terms.

\section{Part 3: Extension of 'father' to same generation, male collateral relations}

We still need to establish the structural basis for $\mathrm{F}$ including the male collateral genealogical relations fffss (= ffbs), ffffsss (= fffbss) ... within the domain of referents for F. We do this as follows. We map any genealogical string expressed as a product of kin types to a corresponding kin-term 
product formed by mapping each kin type in the product of kin types to the kin term that subsumes that kin type, then we compute the reduction of the resulting kin-term product to an irreducible kin term using the structural equations for the terminology, and lastly we assign the genealogical string in question to this kin term. Thus, from the kin type product, fffss (father's father's father's son's son), for example, we form the corresponding kin-term product $S$ o $S$ o F o F o F ('son' of 'son' of 'father' of 'father' of 'father'). ${ }^{28}$ Observe that:

$$
\begin{aligned}
& S \text { o } S \text { o } F \text { o } F \text { o } F=S \text { o }(S \text { o } F) \text { o } F \text { o } F \\
& =S \text { o B o F o F } \\
& =S \circ(B \circ F) \text { o } F \\
& =\mathrm{S} \text { o } \mathrm{F} \text { o } \mathrm{F} \\
& =\mathrm{B} \text { o } \mathrm{F} \\
& =\mathrm{F} \text { (since } \mathrm{S} \text { o } \mathrm{F}=\mathrm{B} \text { and } \mathrm{B} \text { o } \mathrm{F}=\mathrm{F} \text { ), }
\end{aligned}
$$

hence the genealogical relation given by the kin-type product fffss corresponds to the kin-term product $S$ o $S$ o $F$ o $F$ o $F=F$, and so the genealogical relation fffss is included under the kin term F. By a similar argument, any genealogical string of the form, $\mathrm{f}(n$ times $) s(n-1$ times $)$, corresponds to a kin-term product that reduces to $\mathrm{F}$, hence in addition to the genealogical relations $\mathrm{f}$ and $\mathrm{ffs}=\mathrm{fb}$, the sequence of male collateral genealogical relations fffss (= ffbs), ffffsss (= fffbss), ... are also genealogical relations included under the kin term F. In a similar manner, we may determine the predicted assignment of any genealogical string to a kin term by reducing the corresponding kin-term product with the structural equations for generating the kinship terminology to a kin term $\mathrm{K}$ that is irreducible, then assigning the genealogical string to $\mathrm{K}$. We find that the predicted assignments matches the observed assignments for all kin terms, consequently we have an explanatory argument (see Read 2008) for the categories of genealogical relations associated with the kin terms in a classificatory kinship terminology.

It follows, then, that terms such as no-yeb' ('mother') and hä-nib' ('father') in the Iroquois terminology do not refer, as discussed by Shapiro (Chapter 1), to a unitary class of undifferentiated, co-equal members, but to a class with a natural differentiation, starting with a class member who is in a lineal relation to speaker that is then extended to include other members who have a genealogical relationship to speaker in accordance with the

28 As discussed in footnote 23, I use the convention that the order for the product of the kin terms is reversed from that of kin-type products when going from kin-type products to kin-term products. 
computational logic of the kinship terminology for that kin term. Whether we think of the former as the focal member of the class or in some other manner is not critical. What the generative logic makes clear is that the members of the class instantiated through procreation (as it is culturally understood) are necessarily differentiated according to genealogical criteria. ${ }^{29}$ Further, cultural recognition of this differentiation may be made to varying degrees, as exemplified by the Siriono who linguistically mark the differentiation through modifiers meaning 'real' (Scheffler and Lounsbury 1971; see discussion by Shapiro Chapter 1) and by the Tiwi for whom marking, or even acting on, the differentiation, appears to be unimportant (Goodale 1971). In both of these cases, the differentiation derives from the generative logic of a classificatory terminology.

The use of modifiers seems to be a way to resolve the difference between the generative logic that categorises individuals (some with lineal and others with collateral relations to speaker) in the same manner and the genealogical framework that distinguishes between lineal and collateral relations. It is the generative logic that requires the assignment of individuals, some with lineal, or others with collateral, relationship to the same kin-term category. From the perspective of class logic, being assigned to the same class makes them coequal as class members, but the genealogical logic still requires that they be differentiated. Resolution of this disjunction, when it is culturally salient, is achieved by using modifiers that differentiate the primary class members as focal or 'real' kin, thereby distinct from the secondary class members.

Yet why should there be terms requiring this differentiation in the first place? If it is necessary to use a modifier to distinguish genealogical father (mother) from other genealogical relations also referred to by the same kin term, why not simply have a kin term that refers just to the genealogical father (mother) in the first place? Or, if what a kin term designates could change, essentially independent of the other terms, then why have not the kin terms in question each bifurcated into one term that refers only to genealogical father (mother) and a second term that refers to the other genealogical referents? The extensive evidence regarding what seems to be a common practice of using modifiers to make a distinction not otherwise made within the kin terms (see Shapiro Chapter 1) strongly

29 Of course, additional individuals may also be recognised as members of a class through nongenealogical cultural instantiation of kin terms, as discussed by Andrew Strathern (1973) for the Melpa of the New Guinea Highlands. 
suggest that modifiers come into play because making such a change is not possible without violating the logic of the terminology. As shown here, making a distinction between genealogical father (mother) and other genealogical referents through different kin terms would violate the internal consistency of the terminology in question due to the logical connection between conceptualising sibling as a primary relation and having a classificatory terminology. Thus, the frequent use of modifiers may be less a confirmation of a procreative basis for kinship relations and more a way to maintain the logical consistency of a kinship terminology, yet recognising the primacy of the father (mother) relation as it is expressed in the Family Space.

\section{Conclusion}

The explanatory argument presented here resolves the extension problem through appeal to the generative logic of a terminology and whether or not the sibling relation is conceptualised as a primary kinship relation. The generative logic is expressed using culturally salient kin-term products and structural equations. These equations suffice to account for the regularities expressed through the equivalence rules for classificatory terminologies in the following manner. When there is a sibling generating term, the lineal terms are generated not only by an ascending generator, and reciprocally by a descending generator, but also by products with the sibling generator. These products reduce to lineal kin terms, thereby bringing collateral relations into the scope of the genealogical relations subsumed under lineal kin terms, thus accounting for the equivalence rules that extend lineal to collateral genealogical relations, or vice-versa. Consequently, the extension of the genealogical referents of kin terms from lineal to collateral genealogical relations is not mysterious. It follows from the sibling relation being conceptualised (through procreation) by shared parentage. What has, heretofore, hindered recognition of this underlying logic has been the invalid presumption that genealogical kinship relations are first established through procreation and then categorised in some manner, usually by a means assumed to be external to the terminology, with kin terms playing a secondary role as a linguistic labelling system for those categories.

Rather than being based on external factors, the underlying generative logic is based on culturally salient ideas about kinship relations applied to the primary relations making up the Family Space. This leads to 
clarification of the relationship that kinship terminologies have to local ideas about procreation and kinship. The kinship ideas do not simply give biological procreation a cultural overlay. Instead, they lay the foundation for a generative logic that incorporates nonbiological properties such as isomorphism between ascending and descending kin-term structures, reciprocity among kin terms, structural criteria for distinguishing between male-marked and female-marked kin terms, introduction of affinal kin terms either through structural criteria (see, for example, the analysis of the Kariera terminology in Leaf and Read 2012) or through expansion of the core kinship terminology by including an affinal kin term as a generating term (see Read 2007; Leaf and Read 2012 for details), and the culturally different ways that siblings are conceptualised. The last property leads to the disjunction between genealogical structure and the structure of the classificatory kinship terminologies that concerned Morgan, and was addressed formally, though incompletely, through the equivalence rules introduced by Lounsbury and elaborated upon by the work of Scheffler. While the concept of a sibling relation may ultimately have developed from the facts of biological reproduction, viewing kinship terminologies as symbolic (in a mathematical/linguistic sense) computational systems makes evident the way kinship terminology structures can deviate from their biological underpinnings. This allows us to bypass Schneider's antigenealogical position and does not require appeal to other formalisms such as the natural semantic metalanguage formalism developed by Wierzbicka (1992) and co-workers. It permits us to recognise what derives from our biological heritage directly and, at the same time, to appreciate what is new by virtue of our cognitive ability to construct symbolic systems, from whence derives the inherent mathematical character of kinship terminologies.

\section{Acknowledgements}

I would like to thank one of the reviewers of the book manuscript for suggesting that a post-Lounsbury context for the extension problem would be useful, including reference to the writings of Kris Lehman, Ian Keen, the mathematical formalism of Sydney Gould, and further elaboration on the relationship of the work of David Kronenfeld to the ideas of Floyd Lounsbury. This led me to expand the sections titled 'Previous attempts to solve the extension problem' and 'A formal attempt to resolve the extension problem'. 


\section{References}

Allen, Nicholas J., Hilary Callan, Robin Dunbar and Wendy James (eds). 2011. Early Human Kinship: From Sex to Social Reproduction. London, Wiley-Blackwell.

Ballonoff, Paul A. (ed.). 1974. Genealogical Mathematics. The Hague: Mouton.

Barnard, Alan. 2010. 'When individuals do not stop at the skin'. In Social Brain, Distributed Mind, edited by Robin Dunbar, Clive Gamble and John Gowlett, 249-67. London: Oxford University Press. doi.org/ $10.5871 / \mathrm{bacad} / 9780197264522.003 .0012$

Baudouin, C. and H. Blaikie. 2014. 'Surrogacy in Quebec: First legal case'. Canadian Fertility and Andrology Society. Online: www.cfas.ca/ index.php?option $=$ com_content $\&$ view $=$ article $\& i d=772 \&$ Itemid $=$ 523.k (accessed 23 September 2014).

Behrens, Clifford Allen. 1984. 'Shipibo ecology and economy: A mathematical approach to understanding human adaption'. PhD dissertation. Department of Anthropology, University of California, Los Angeles.

Behrens, Clifford and Dwight Read. 1993. 'Anthropology: Moving from task-driven to science-driven computing'. Social Science Computer Review 11(4): 429-51.

Bennardo, Giovanni and Dwight Read. 2005. 'The Tongan kinship terminology: Insights from an algebraic analysis'. Mathematical Anthropology and Culture Theory 2(1). Online: www. math ematicalanthropology.org/Pdf/Bennardo \&Read 1205.pdf (accessed 22 September 2010).

- 2007. 'Cognition, algebra, and culture in the Tongan kinship terminology'. Journal of Cognition and Culture 7(1-2): 49-88. doi.org/10.1163/156853707X171810

Biersack, Aletta. 1982. 'Tongan exchange structures: Beyond descent and alliance'. The Journal of the Polynesian Society 91(2): 181-212.

Buchler, Ira R. and Henry A. Selby. 1968. Kinship and Social Organization: An Introduction to Theory and Method. New York: The Macmillan Company. 
Burridge, Kenelm O.L. 1959-1960. 'Siblings in Tangu'. Oceania 30: 127-54. doi.org/10.1002/j.1834-4461.1959.tb00215.x

Chomsky, Noam. 1963. 'Formal properties of grammars'. In Handbook of Mathematical Psychology, edited by Robert Duncan Luce, Robert R. Bush and Eugene Galanter, vol. 2, 323-41. New York: Addison Wesley.

Counts, Dorothy Ayres and David R. Counts. 1983. 'Father's water equals mother's milk: The conception of parentage in Kaliai, West New Guinea'. Mankind 14(1): 46-56. doi.org/10.1111/j.1835-9310.1983. tb01250.x

D’Andrade, Roy G. 1970. 'Structure and syntax in the semantic analysis of kinship terminologies'. In Cognition: A Multiple View, edited by Paul L. Garvin, 87-143. New York: Spartan Books.

Douglas, Mary. 1966. Purity and Danger: An Analysis of the Concepts of Pollution and Taboo. London: Routledge \& Kegan Paul. doi.org/ $10.4324 / 9780203361832$

Dousset, Laurent. 2005. 'Structure and substance: combining "classic" and "modern" kinship studies in the Australian Western Desert'. The Australian Journal of Anthropology 16(1): 18-30. doi.org/10.1111/ j.1835-9310.2005.tb00107.x

Dunbar, Robin, Clive Gamble, John Gowlett (eds). 2010. Social Brain, Distributed Mind. London: Oxford University Press.

Dziebel, German Valentinovich. 2007. The Genius of Kinship: The Phenomenon of Human Kinship and the Global Diversity of Kinship Terminologies. Youngstown: Cambria Press.

El Guindi, Fadwa and Dwight Read. 2012. 'Westermarck hypothesis reconsidered: A comment on Kushnick and Fessler'. Current Anthropology 53(1): 134-35. doi.org/10.1086/663576

Evans-Pritchard, E.E. 1929. 'The study of kinship in primitive societies'. Man 29: 190-94. doi.org/10.2307/2789028

1932. 'The nature of kinship extensions'. Man 32: 12-15. doi.org/ $10.2307 / 2789766$ 
Feinberg, Richard and Martin Ottenheimer (eds). 2001. The Cultural Analysis of Kinship: The Legacy of David M. Schneider. Urbana, IL: University of Illinois Press.

Freire-Marreco, B.W., Sir J.L. Myres and the British Association for the Advancement of Science (eds). 1912. Notes and Queries on Anthropology. London: Royal Anthropological Institute.

Garvin, Paul L. (ed.). 1970. Cognition: A Multiple View. New York: Spartan Books.

Good, Anthony. 1981. 'Prescription, preference and practice: Marriage patterns among the Kondaiyankottai Maravar of South India'. Man (N. S.) 16(1): 108-29. doi.org/10.2307/2801978

Goodale, Jane C. 1971. Tiwi Wives: Study of the Women of Melville Island, North Australia. Seattle: University of Washington Press.

Goodenough, Ward Hunt (ed.). 1964. Explorations in Cultural Anthropology: Essays in Honor of George Peter Murdock. New York: McGraw Hill.

Goody, Jack (ed.). 1973. The Character of Kinship. Cambridge: Cambridge University Press.

Gough, E. Kathleen. 1959. 'The Nayars and the definition of marriage'. Journal of the Royal Anthropological Institute of Great Britain and Ireland 89(1): 23-34. doi.org/10.2307/2844434

Gould, Sydney Henry. 2000. A New System for the Formal Analysis of Kinship. Edited, annotated and with an introduction by David B. Kronenfeld. Lanham: University Press of America.

Gow, Peter. 1991. An Amazonian Myth and its History. Oxford: Oxford University Press.

Hocart, A.M. 1937. 'Kinship systems'. Anthropos 32: 545-51.

Jones, Doug and Bojka Milicic (eds). 2010. Kinship, Language, and Prehistory: Per Hage and the Renaissance in Kinship Studies. Salt Lake City: University of Utah Press.

Kaplan, Joanna O. 1975. The Piaroa: A People of the Orinoco Basin-A Study of Kinship and Marriage. Oxford: Clarendon Press. 
Keen, I. 1985. 'Definitions of kin'. Journal of Anthropological Research 41(1): 62-90. doi.org/10.1086/jar.41.1.3630271

Kelly, Raymond C. 1977. Etoro Social Structure: A Study in Structural Contradiction. Ann Arbor, MI: University of Michigan Press.

Knight, Chris. 2011. 'Early human kinship was matrilineal'. In Early Human Kinship: From Sex to Social Reproduction, edited by Nicholas J. Allen, Hillary Callan, Robin Dunbar and Wendy James, 61-82. London: Wiley-Blackwell.

Kroeber, A.L. 1909. 'Classificatory system of relationship'. Journal of the Royal Anthropological Institute 39: 77-84. doi.org/10.2307/2843284

Kronenfeld, David B. 1980. 'Particularistic or universalistic analyses of Fanti kin-terminology: The alternative goals of terminological analysis'. Man (n.s.) 15(1) (1980): 151-69. doi.org/10.2307/2802007; republished in Fanti Kinship and the Analysis of Kinship Terminologies, edited by Kronenfeld, 53-70. Urbana: University of Illinois Press, 2009 (page references to 2009 edition).

Kronenfeld, David B. (ed.). 2009. Fanti Kinship and the Analysis of Kinship Terminologies. Urbana: University of Illinois Press.

Kronenfeld, David B., Giovanni Bennardo, Victor C. de Munck and Michael D. Fischer (eds). 2011. A Companion to Cognitive Anthropology. London: Blackwell Publishing Ltd.

Leach, Edmund R. 1958. 'Concerning Trobriand clans and the kinship category tabu'. The Developmental Cycle Domestic Groups, edited by Jack Goody, 120-45. Cambridge: Cambridge University Press.

Leaf, Murray J. 2006. 'Experimental-formal analysis of kinship'. Ethnology 45(4): 305-30. doi.org/10.2307/20456604

Leaf, Murray J. and Dwight Read. 2012. The Conceptual Foundation of Human Society and Thought: Anthropology on a New Plane. Lanham, MD: Lexington Books.

Leavitt, Gregory C. 2005. Incest and Inbreeding Avoidance: A Critique of Darwinian Social Science. Lewiston: Edwin Mellen Press. 
Lehman, Frederick K. 2011. 'Kinship theory and cognitive theory in anthropology'. A Companion to Cognitive Anthropology, edited by David B. Kronenfeld, Giovanni Bennardo, Victor C. de Munck and Michael D. Fischer, 254-69. London: Blackwell.

Lehman, F.K. and K.G. Witz. 1974. 'Prolegomena to a formal theory of kinship'. In Genealogical Mathematics, edited by Paul A. Ballonoff, 11-134. The Hague: Mouton.

Levinson, Stephen C. 2006. 'Matrilineal clans and kin terms on Rossel Island'. Anthropological Linguistics 48(1): 1-43.

Liu, Pin-Hsiung. 1986. Foundations of Kinship Mathematics. Taipei: Academia Sinica Press.

Lounsbury, Floyd G. 1964. 'A formal account of Crow- and Omaha-type kinship terminologies'. In Explorations in Cultural Anthropology: Essays in Honor of George Peter Murdock, edited by Ward Hunt Goodenough, 351-93. New York: McGraw Hill.

- 1965. 'Another view of the Trobriand kinship categories'. In American Anthropologist 67(5):142-85. doi.org/10.1525/aa.1965 .67.5.02a00770

Luce, Robert Duncan, Robert R. Bush and Eugene Galanter (eds). 1963. Handbook of Mathematical Psychology. New York: Addison Wesley.

Malinowski, Bronisław. 1927a. Sex and Repression in Savage Society. London: Routledge.

—. 1927b. The Father in Primitive Psychology. New York: W.W. Norton and Company.

—. 1929. 'Marriage'. Encyclopedia Britannica 14: 940-50.

—. 1930. 'Kinship'. Man (n.s.) 30: 19-29. doi.org/10.2307/2789869

- 1962. Sex, Culture and Myth. New York: Harcourt, Brace \& World, Inc.

Marshall, Lorna. 1976. The !Kung of Nyae Nyae. Cambridge: Harvard University Press. doi.org/10.4159/harvard.9780674180574

Moller, M.S.G. 1958. 'Bahaya customs and beliefs in connection with pregnancy and childbirth'. Tanganiyka Notes and Records 50: 112-17. 
Morgan, Lewis H. 1871. Systems of Consanguinity and Affinity in the Human Family. Washington, DC: The Smithsonian Institute.

Murdock, George Peter. 1949. Social Structure. New York, Macmillan.

Nayacakalou, R.R. 1955. 'The Fijian system of kinship and marriage (Part I)'. Journal of the Polynesian Society 64(1): 44-55.

Newton, Sir Isaac. 1782 [1672]. Isaaci Newtoni Opera Quae Exstant Omnia. Commentariis illustrabat Samuel Horsley, Tomas 4. London: Excudebat Joannes Nichols.

Radcliffe-Brown, A.R. 1913. 'Three tribes of Western Australia'. Journal of the Royal Anthropological Institute 43: 143-94. doi.org/10.2307/ 2843166

- - 1950. 'Introduction'. In African Systems of Kinship and Marriage, edited by A.R. Radcliffe-Brown and Daryll Forde, 1-85. Oxford: Oxford University Press.

Radcliffe-Brown A.R. and Daryll Forde (eds). 1950. African Systems of Kinship and Marriage. Oxford: Oxford University Press.

Rantala, Markus J. and Ursula M. Marcinkowska. 2011. 'The role of sexual imprinting and the Westermarck effect in mate choice in humans'. Behavioral Ecology and Sociobiology 65: 859-73. doi.org/10.1007/ s00265-011-1145-y

Read, Dwight W. 1984. 'An algebraic account of the American kinship terminology [and comments and reply]'. Current Anthropology 25(4): 417-49. doi.org/10.1086/203160

_- 2000. 'Formal analysis of kinship terminologies and its relationship to what constitutes kinship (complete text)'. Mathematical Anthropology and Cultural Theory 1(1): 1-46.

—_. 2001. 'What is kinship?' In The Cultural Analysis of Kinship: The Legacy of David M. Schneider, edited by Richard Feinberg and Martin Ottenheimer, 78-117. Urbana, IL: University of Illinois Press.

- 2002. 'Cultural construct + instantiation $=$ constructed reality'. Human Complex Systems. Paper DWR2002. Online: repositories. cdlib.org/hcs/DWR2002 (accessed 31 May 2017).

—_. 2007. 'Kinship theory: A paradigm shift'. Ethnology 46(4): 329-64. 
- 2008. 'A formal explanation of formal explanation'. Structure and Dynamics 3(2): 1-16. Online: escholarship.org/uc/item/91z973j6 (accessed 14 July 2017).

- 2010a. 'The generative logic of Dravidian language terminologies'. Mathematical Anthropology and Cultural Theory 3(7). Online: www.mathematicalanthropology.org/pdf/Read.0810.pdf (accessed 24 September 2010).

- 2010b. 'The logic and structure of kinship terminologies: Implications for theory and historical reconstruction'. In Kinship, Language, and Prehistory: Per Hage and the Renaissance in Kinship Studies, edited by Doug Jones and Bojka Milicic, 152-72. Salt Lake City: University of Utah Press.

—. 2011. 'Mathematical representation of cultural constructs'. In A Companion to Cognitive Anthropology, edited by David Kronenfeld, Giovanni Bennardo, Victor C. de Munck and Michael D. Fischer, 229-53. London: Blackwell Publishing Ltd. doi.org/10.1002/ 9781444394931.ch13

- 2013. 'A new approach to forming a typology of kinship terminology systems: From Morgan and Murdock to the present'. Structure and Dynamics 6(1). Online: escholarship.org/uc/item/0ss6j8sh (accessed 9 August 2017).

- 2014. 'Incest taboos and kinship: A biological or a cultural story?' Reviews in Anthropology 43(2): 150-75. doi.org/10.1080/00938157.2 014.903151

Read, Dwight W. and Clifford A. Behrens. 1990. 'KAES: An expert system for the algebraic analysis of kinship terminologies'. Journal of Quantitative Anthropology 2(4): 353-93.

Read, Dwight W., Michael D. Fischer and Kris Lehman (Chit Hlaing). 2014. 'The cultural grounding of kinship: A paradigm shift'. L'Homme 210(2): 63-89. doi.org/10.4000/lhomme.23550

Reining, Priscilla (ed.). 1972. Kinship Studies in the Morgan Centennial Year. Washington: The Anthropological Society of Washington.

Rivers, William H.R. 1910. 'The genealogical method of anthropological enquiry'. Sociological Review 3(1): 1-12. doi.org/10.1111/j.1467954X.1910.tb02078.x 
1912. 'A general account of method'. In Notes and Queries on Anthropology, edited by B.W. Freire-Marreco, Sir J.L. Myres and the British Association for the Advancement of Science, 108-27. London: Royal Anthropological Institute.

—_. 1914. The History of Melanesian Society, vol. 1. Cambridge: Cambridge University Press.

Sahlins, Marshall. 1962. Culture and Nature on a Fijian Island. Ann Arbor, University of Michigan Press. doi.org/10.3998/mpub.9690566

Scheffler, Harold W. 1972. 'Kinship semantics'. Annual Reviews in Anthropology 1: 309-28.

—_. 1978. Australian Kin Classification. Cambridge: Cambridge University Press. doi.org/10.1017/CBO9780511557590

—_. 1986. 'Extension rules and "generative models"'. American Ethnologist 13(2): 369-70. doi.org/10.1525/ae.1986.13.2.02a00130

- 2002. Review of A New System for the Formal Analysis of Kinship by Sydney H. Gould. Journal of Anthropological Research 58: 295-96. doi.org/10.1086/jar.58.2.3631055

Scheffler, Harold W. and Floyd G. Lounsbury. 1971. A Study in Structural Semantics: The Siriono Kinship System. Englewood Cliffs, NJ: Prentice Hall.

Schieffelin, Edward L. 1976. The Sorrow of the Lonely and the Burning of the Dancers. New York: Palgrave Macmillan. doi.org/ $10.1057 / 9781403981790$

Schneider, David M. 1972. 'What is kinship all about?' In Kinship Studies in the Morgan Centennial Year, edited by Priscilla Reining, 32-63. Washington: The Anthropological Society of Washington.

- - 1984. A Critique of the Study of Kinship. Ann Arbor: University of Michigan Press. doi.org/10.3998/mpub.7203

Seligman, Brenda Z. 1929. 'Incest and descent: Their influence on social organization'. Journal of the Royal Anthropological Institute of Great Britain and Ireland 59: 231-72. doi.org/10.2307/2843567 
Shapiro, Warren. 1982. 'Review: The place of cognitive extensionism in the history of anthropological thought'. The Journal of the Polynesian Society 91(2): 257-97. www.jstor.org/stable/20705647

Shih, Chuan-kang. 2010. Quest for Harmony: The Moso Traditions of Sexual Union and Family Life. Stanford: Stanford University Press.

Shor, Eran and Dalit Simchai. 2009. 'Incest avoidance, the incest taboo, and social cohesion: Revisiting Westermarck and the case of the Israeli kibbutzim'. American Journal of Sociology 114(6): 1803-842. doi.org/ $10.1086 / 597178$

- 2012. 'Exposing the myth of sexual aversion in the Israeli kibbutzim: A challenge to the Westermarck hypothesis'. American Journal of Sociology 117(5): 1509-513. doi.org/10.1086/665522

Sigarimbun, Masri. 1975. Kinship, Descent and Alliance among the Karo Batak. Berkeley, CA: University of California Press.

Strathern, Andrew. 1973. 'Kinship, descent and locality: Some New Guinea examples'. In The Character of Kinship, edited by Jack Goody, 21-34. Cambridge: Cambridge University Press.

Turner, Jonathan H. and Alexandra Maryanski. 2005. Incest: Origins of the Taboo. Boulder: Paradigm.

Unwin, J.D. 1929. 'The classificatory system of relationship'. Man 29: 164.

Vilaca, Aparecida. 2002. 'Making kin out of others in Amazonia'. Journal of the Royal Anthropological Institute 8(2): 347-65.

Wierzbicka, Anna. 1992. Semantics, Culture, and Cognition: Universal Human Concepts in Culture-Specific Configurations. New York: Oxford University Press.

—. 2016. "Back to "mother" and "father": Overcoming the Eurocentrism of kinship studies through eight lexical universals'. Current Anthropology 57(4): 408-29. doi.org/10.1086/687360

Wolf, Arthur P. and Willian H. Durham (eds). 2004. Inbreeding, Incest, and the Incest Taboo: The State of Knowledge at the Turn of the Century. Stanford: Stanford University Press. 
This text is taken from Focality and Extension in Kinship: Essays in Memory of Harold W. Scheffler, edited by Warren Shapiro, published 2018 by ANU Press, The Australian National University, Canberra, Australia.

doi.org/10.22459/FEK.04.2018.02 